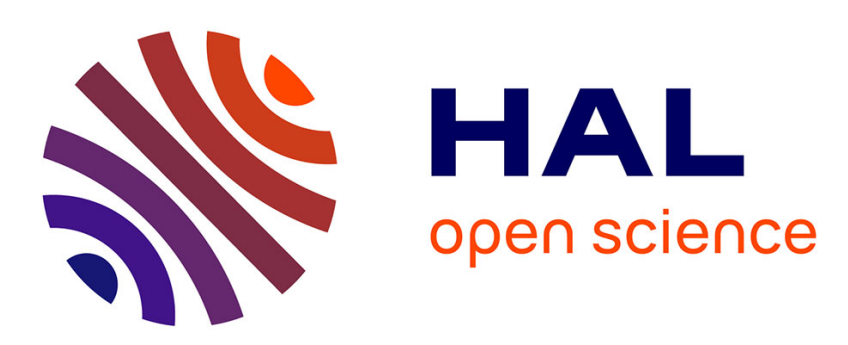

\title{
New phenomena in Organometallic-Mediated Radical Polymerization (OMRP) and perspectives for control of less active monomers \\ Rinaldo Poli
}

\section{To cite this version:}

Rinaldo Poli. New phenomena in Organometallic-Mediated Radical Polymerization (OMRP) and perspectives for control of less active monomers. Chemistry - A European Journal, 2015, 21 (19), pp.6988-7001. 10.1002/chem.201500015 . hal-01919609

\section{HAL Id: hal-01919609 \\ https://hal.science/hal-01919609}

Submitted on 29 Jul 2021

HAL is a multi-disciplinary open access archive for the deposit and dissemination of scientific research documents, whether they are published or not. The documents may come from teaching and research institutions in France or abroad, or from public or private research centers.
L'archive ouverte pluridisciplinaire HAL, est destinée au dépôt et à la diffusion de documents scientifiques de niveau recherche, publiés ou non, émanant des établissements d'enseignement et de recherche français ou étrangers, des laboratoires publics ou privés. 


\section{New phenomena in organometallic-mediated radical polymerization (OMRP) and perspectives for control of less active monomers}

\begin{abstract}
Rinaldo Poli*[a]
Abstract: The impact of reversible bond formation between a growing radical chain and a metal complex (OMRP equilibrium) to generate an organometallic intermediate/dormant species in controlled radical polymerization is analyzed with emphasis on the interplay between this and other one-electron processes involving the metal complex, which include halogen transfer in atom transfer radical polymerization (ATRP), $\mathrm{H}$-atom transfer in catalytic chain transfer (CCT), and catalytic radical termination (CRT). The challenges facing the controlled polymerization of "less active monomers" (LAMs) are outlined and, after reviewing the recent achievements of OMRP in this area, the perspectives of this technique are analyzed.
\end{abstract}

\section{Introduction}

Polymer science and macromolecular synthesis by polymerization processes combine, perhaps to a greater degree than any other branch of science, fundamental knowledge and practical utility for improving our life standard. The latter is echoed in the 1980 statement of Lord Alexander Todd, President of the Royal Society of Chemistry: "I am inclined to think that the development of polymerization is perhaps the biggest thing chemistry has done, where it has had the biggest effect on everyday life". ${ }^{[1]}$ The degree of fundamental scientific content of polymer science is reflected by the regular and continuous Nobel Price recognition of scientists for their conceptual advances in this discipline, starting with Hermann Staudinger in 1953. There have been several quantum leaps in macromolecular science, such as (to name just a few) the introduction on the market of Nylon in the 30's and of low-density polyethylene in the 40's, the discovery of olefin stereoregular polymerization in the 50's (Nobel 1963), the discovery of conducting polymers in the 70's (Nobel 2000) and the development of single site metallocene catalysts in the 90's.

The turn of the millennium has witnessed a new change of gear in polymer chemistry research with a focus switch from the development and improvement of bulk commodity plastics to the production of higher added value functionalized macromolecules for specialty applications. ${ }^{[2]}$ This was made possible by learning how to control macromolecular growth for the more functionalitytolerant radical polymerization. While conceptually simple, the power of this strategy cannot be overemphasized since it opens

[a] Prof. R. Poli

CNRS, LCC (Laboratoire de Chimie de Coordination)

and Université de Toulouse, UPS, INPT

205 route de Narbonne, BP 44099

F-31077, Toulouse Cedex 4, France

and

Institut Universitaire de France,

103 bd Saint-Michel,

75005, Paris, France

E-mail: rinaldo.poli@Icc-toulouse.fr access to macromolecular architectures that are essentially limited only by one's imagination. The method rests on a continuous and reversible exchange between a tiny fraction of active radical chains and a major proportion of latent chains, i.e. chains kept in a dormant state by a moderating agent. The position of this equilibrium and its dynamics insures the reduction (control) of the unwanted spontaneous terminations by coupling and disproportionation while the chain growth process takes place in a controlled fashion, potentially reaching high molecular weights with extremely narrow molecular weight distributions. Various specific techniques have been developed on the basis of the moderating agent nature; they can all be grouped into two families depending on the exchange mechanism as dissociative (a) or associative (b), see Scheme 1. Techniques based on dissociative processes may also be termed "reversible termination" (RT) methods, whereas those based on associative exchange are also termed "degenerative transfer" (DT) methods. IUPAC recommends to collectively call all controlled radical polymerizations as "reversible deactivation radical polymerizations" (RDRPs). ${ }^{[3]}$ "Nitroxide mediated polymerization" or NMP (T $=$ stable nitroxide radical $)^{[4]}$ is one of the most successful RT techniques and "reversible addition-fragmentation chain transfer" or RAFT ( $T=$ thiocarbonylthio fragment) is the most popular DT method. ${ }^{[5]}$ In "organometallic-mediated radical polymerization" (OMRP), ${ }^{[6]}$ which is of interest in this article, $\mathrm{T}$ is a transition metal complex generating an organometallic dormant species with a homolytically weak metal-carbon bond and can function by both types of exchange, (a) and (b).

(a)

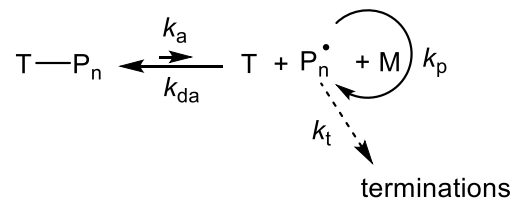

(b)

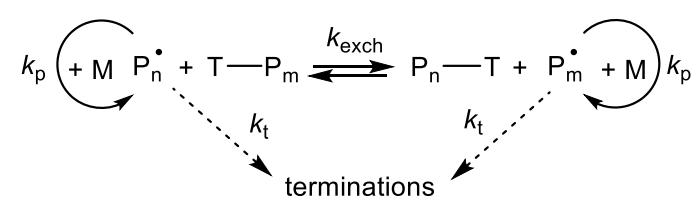

Scheme 1. Dissociative (a) and associative (b) exchange equilibria between growing radical chains and latent chains. $\mathrm{T}=$ radical trapping species; $\mathrm{P}_{\mathrm{n}}{ }^{\circ}, \mathrm{Pm}_{\mathrm{m}}$ = growing radical chains; $\mathrm{M}=$ monomer; $k_{\mathrm{a}}, k_{\mathrm{da}}, k_{\mathrm{exch}}, k_{\mathrm{p}}, k_{\mathrm{t}}=$ activation, deactivation, exchange, propagation and termination rate constants.

Phenomenal advances in this area have followed the development of "atom-transfer radical polymerization" or ATRP, which is an extension of the metal-catalyzed "atom-transfer radical addition" (ATRA) of activated alkyl halides to olefins. ${ }^{[7]}$ Although the first reports of this approach ${ }^{[8]}$ have followed those of OMRP by about a year, ${ }^{[9]}$ ATRP has rapidly become a preferred 
controlling method because the metal complex plays a catalytic role and the recovered polymer chains are capped by a halogen atom, whereas in OMRP the metal complex remains stoichiometrically incorporated as the macromolecule chain end. Thus, technical polymer synthesis is more attractive by ATRP because only small amounts of metal complex may contaminate the polymer and can be easily removed. On the other hand, large amounts of metal must be removed from a polymer made by OMRP in order to obtain metal-free materials. ATRP belongs to the family of dissociative exchange methods (Scheme 1a) where $\mathrm{T}$ is a halogen atom, usually a chloride or a bromide, but a metal complex capable of forming a bond with the halogen must be present to compensate the energy needed to homolytically break the carbon-halogen bond with the energy released in the formation of the metal-halogen bond. ATRP efficiently controls a wide variety of functional monomers including styrenics, acrylates, methacrylates, the corresponding (meth)acrylamides, acrylonitrile and several other monomers associated to stabilized radicals (socalled "more reactive monomers" or MAMs) but has failed to provide suitable control for less reactive monomers (LAMs), for which the active radical establishes stronger bonds with the trapping agent $\mathrm{T}$. These are monomers such as vinyl esters and amides, vinyl chlorides and other halogenated olefins, and simple alkenes. As will be argued in this article, OMRP is more effective in this area and has much greater promise than ATRP or any other method for further advances in LAM controlled polymerization. In order to assess the potentials and limitations of OMRP, we must appreciate how this controlling mechanism interplays with other phenomena.

\section{Mechanistic interplays of OMRP}

\section{(a) With ATRP}

In the introduction, we have already seen two different ways in which a metal complex operates in controlled radical polymerization: as a catalyst in ATRP and as a radical trap in OMRP. The requirements for both processes are the same: the metal must be able to increase both its coordination number and its formal oxidation state by one unit. Hence, it is possible for the same complex and the same radical chain to be involved in both processes simultaneously. This phenomenon was first evidenced for the polymerization of styrene moderated by a family of Mo $\mathrm{III}^{\mathrm{I}}$ 17-electron complexes ${ }^{[10]}$ and has since been highlighted for a number of other systems. ${ }^{[11]}$ The way in which these processes interplay is schematically shown in Figure 1.

When a polymerization is set up under ATRP conditions $\left(\mathrm{R}_{0^{-}}\right.$ $\mathrm{X}$ initiator $+\mathrm{Mt} \mathrm{t}^{\mathrm{x}} / \mathrm{L}$ catalyst) or under "reverse ATRP" conditions $\left(\mathrm{R}_{0}{ }^{\cdot}\right.$ from a conventional radical source $+\mathrm{Mt}^{\mathrm{x}+1}(\mathrm{X}) / \mathrm{L}$ trapping species), given that the ATRP equilibrium is substantially shifted toward the dormant species $\mathrm{P}_{\mathrm{n}}-\mathrm{X}$, a large amount of $\mathrm{Mt} \mathrm{t}^{\mathrm{x}} / \mathrm{L}$ remains present to also engage in the OMRP trapping equilibrium with the radical. The relative contribution of each controlling mechanism depends on the relative stability of the two dormant states $\left(\Delta G_{\text {ATRP }}\right.$ vs. $\left.\Delta G_{\text {OMRP }}\right)$ and on the relative deactivation barriers $\left(\Delta G^{\ddagger}{ }_{d a, A T R P}\right.$ vs. $\Delta \mathrm{G}_{\mathrm{da}, \mathrm{OMRP}}^{\ddagger}$ ). In the vast majority of publications detailing ATRP processes, the potential contribution of reversible OMRP trapping has not been addressed. Certainly, the contribution of OMRP may be neglected in many cases, but even for certain systems that undoubtedly operate by ATRP (the recovered polymer chains were $100 \%$ halogen terminated) the contribution of OMRP trapping in slowing down the polymerization rate was shown to be significant. ${ }^{[12]}$ On the other hand, there are polymerization processes that, although set up under ATRP conditions, were shown to proceed with significant OMRP trapping contribution, ${ }^{[10}$, 11f] or even by OMRP only. ${ }^{[11 \mathrm{~b}, 11 \mathrm{~d}]}$ As discussed in a previous review, ${ }^{[13]}$ depending on the absolute and relative values of $\Delta G_{\text {ATRP }}$ and $\Delta G_{\text {OMRP }}$, various limiting situations may be envisaged around the general scenario of the synergistic control by both equilibria: no polymerization, control by ATRP only, control by OMRP only, polymerization without control, and irreversible 1electron oxidative addition. It now becomes apparent why ATRP fails to control LAM polymerization: radicals associated to LAMs yield stronger $\mathrm{C}-\mathrm{X}$ bonds in the ATRP dormant species and activation becomes difficult or impossible. ${ }^{[14]}$ This energy cost could theoretically be compensated by selecting an $\mathrm{Mt} \times / \mathrm{L}$ able to form a stronger bond with $\mathrm{X}$. However, such a complex will then a fortiori form a stronger bond with the more reactive radical associated to the LAM therefore leading to a stable (i.e. difficult to reactivate) OMRP dormant species.

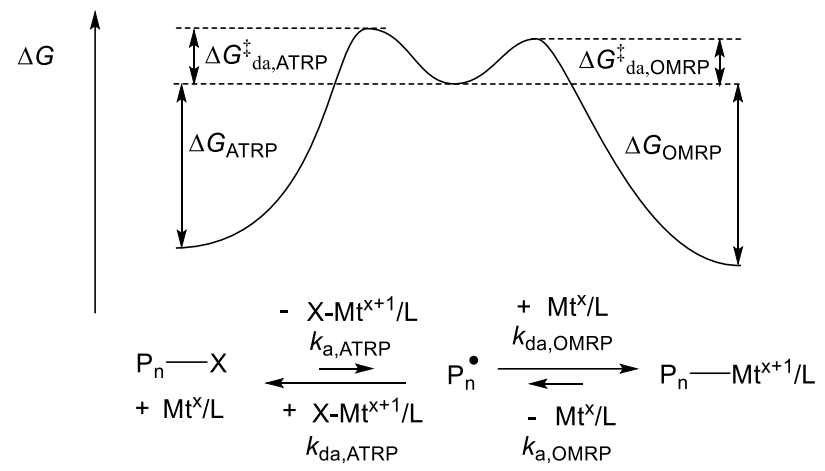

Figure 1. Interplay of ATRP and OMRP processes for a given metal complex $M t^{x} / L$ and growing radical chain $P_{n} \cdot$ where $M t$ represents the metal, $x$ its formal oxidation state, $/ L$ the ligand coordination sphere, and $X$ is a halogen atom (usually a chlorine or a bromine).

Setting up a polymerization under OMRP conditions, namely from $\mathrm{Mt} \times / \mathrm{L}$ plus a conventional radical source or from a suitable organometallic $\mathrm{R}_{0}-\mathrm{Mt}^{\mathrm{x}+1} / \mathrm{L}$ complex (if available), cannot provide access to the ATRP equilibrium if the controlling system is devoid of halogen atoms, such as for instance the Co" porphyrin or cobaloxime systems used in the first OMRP reports. ${ }^{[9]}$ Hence, it is possible in principle to select a metal and engineer a metal coordination sphere to render the metal-carbon bond sufficiently weak in a homolytic sense for any LAM of interest (vide infra). Even when halogen atoms are absent, however, there are other ways in which transition metals may interact with organic 


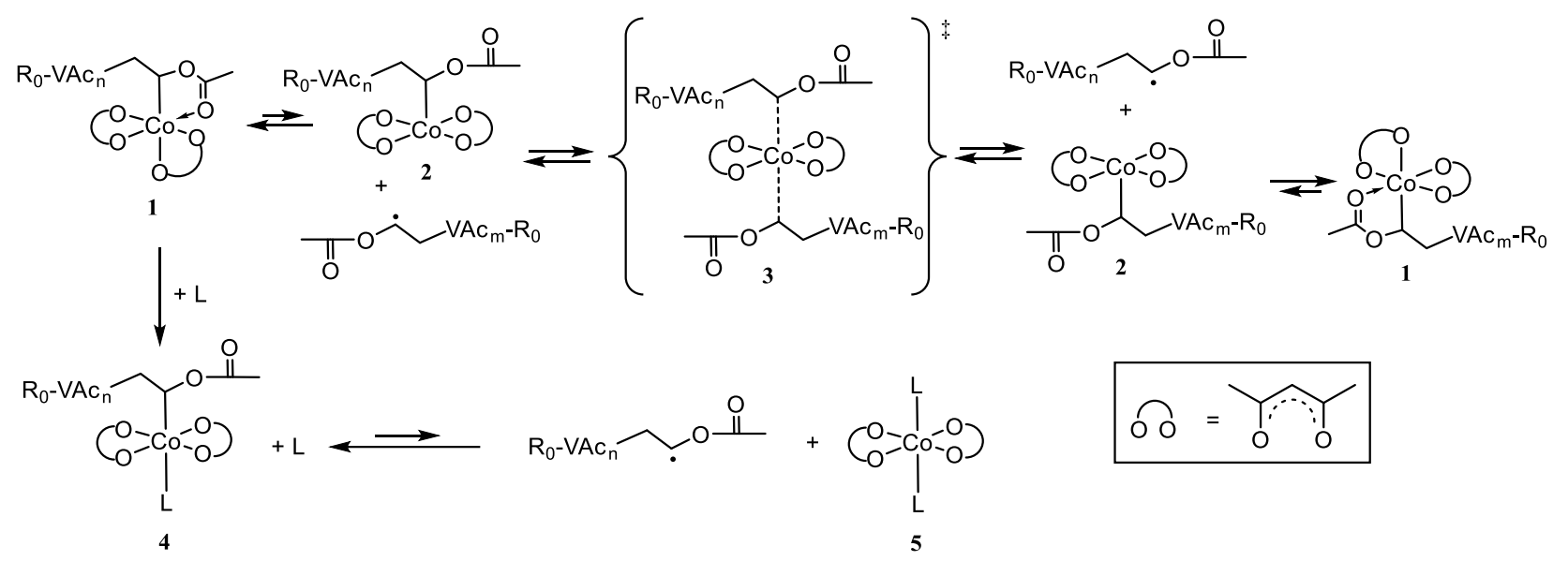

Scheme 2. Associative and L-activated dissociative radical exchange in the OMRP of vinyl acetate controlled by [Co(acac)2].

radicals $^{[15]}$ and interfere with the OMRP controlled chain growth, as detailed in the next sections.

\section{(b) Dissociative and associative OMRP}

One possible interference comes from the associative exchange between the organometallic dormant species and excess radicals leading under suitable conditions $\left(k_{\text {exch }}>k_{\mathrm{p}}\right)$ to controlled polymerization by degenerate transfer. In order to allow this exchange, the metal complex must have an open coordination site for docking the incoming radical. In the initial induction phase of the bulk radical polymerization of vinyl acetate (VAc, a less active monomer) controlled by 4-coordinate [ $\left.\mathrm{Co}(\mathrm{acac})_{2}\right](\mathrm{acac}=$ acetylacetonate), ${ }^{[16]}$ the thermally released primary radicals are trapped irreversibly leading to short [Co(acac $\left.)_{2}\right]$-capped PVAc chains and no polymerization occurs. Only when the amount of radicals exceeds the amount of cobalt, the excess radicals start the polymerization, which is kept in a controlled regime by the degenerative exchange process. Although the CollI dormant species has a saturated 18-elecron configuration through chelation of the Co-bound monomer carbonyl group (1 in Scheme $2),{ }^{[17]}$ the chelate opens up at a small energy cost and the associative exchange takes place via the unsaturated 5coordinate intermediate 2 and the associative transition state $\mathbf{3}$. The presence of coordinating additives $L$ (e.g. pyridine, DMSO, DMF, water) blocks the free coordination site of $\mathbf{2}$ through formation of $\mathbf{4}$ and stops the associative exchange, but also promotes dissociation through stabilization of the Coll product as the ligand adduct $\left[\mathrm{Co}(\mathrm{acac})_{2}(\mathrm{~L})_{2}\right](5)$. Therefore, in the presence of $L$ the polymerization becomes controlled by the dissociative mechanism with no apparent induction phase. ${ }^{[18]}$ The bulky tetramesitylporphyrincobalt complex, [Co(TMP)], also shows interplay of RT and DT modes of control. For instance, the polymerization of methyl acrylate (MA) in benzene at $60^{\circ} \mathrm{C}$ is controlled but slow when using $<1$ equiv of primary radicals per cobalt, but a faster process occurred by DT, after an initial slow $\mathrm{RT}$ conversion before complete transformation of $\mathrm{Co}{ }^{\prime \prime}$ to $\mathrm{RCo}^{\prime \prime \prime}$, when using excess initiator. ${ }^{[19]}$

\section{(c) With CCT}

Catalytic chain transfer (CCT), a metal-catalyzed transfer to monomer, involves the same partners as the OMRP trapping equilibrium: the growing radical chain and the metal complex in its reduced state, $\mathrm{Mt} \times / \mathrm{L}$. This phenomenon, discovered and initially developed by Russian scientists in the $70 s,{ }^{[20]}$ is now well-known and has its own interest and practical applications, ${ }^{[21]}$ but its presence negatively affects the metal ability to control chain growth. Its mechanism involves $\mathrm{H}$-atom transfer from the growing radical chain to the metal atom with generation of a hydride intermediate $\mathrm{H}-\mathrm{Mt}^{\mathrm{x}+1} / \mathrm{L}$ and a polymer chain with an unsaturated chain end, see Figure 2. A new chain is then started by the reverse $\mathrm{H}$-atom transfer from the metal to a monomer. The competition between OMRP trapping and $\mathrm{H}$-atom transfer is controlled by the relative height of the activation barriers, $\Delta G_{\text {da,OMRP }}^{\ddagger} v s . \Delta G^{\ddagger}$. The hydride intermediate probably has a relatively high energy because stable hydridocobalt(III) complexes stabilized by hard (O or $\mathrm{N}$-based donor) ligands are rare. ${ }^{[22]}$ Growing contribution of CCT in an OMRP process yields polymers with lower than targeted molecular weights and broader molecular weight distributions. Conversely, growing contribution of OMRP trapping in a CCT process results in increased molecular weights and a polymerization rate decrease.

A point of interest is the ability of the same metal and with the same pair of adjacent oxidation states, notably Co ${ }^{1 / 1 / I}$, to yield either efficient OMRP control or efficient CCT depending on the coordination sphere. Cobalt is indeed the metal leading to the most efficient OMRP controlling systems developed so far, ${ }^{[23]}$ as well as to the most efficient chain transfer catalysts. ${ }^{\text {[21a] Certain }}$ trends resulting from substituent effects on the CCT efficiency have been outlined for certain families of catalysts, for instance porphyrin complexes. However, how the ligand coordination sphere individually modulates $\Delta G^{\ddagger}{ }_{\text {da, OMRP }} \Delta G^{\ddagger}{ }_{H}$ and $\Delta G_{\text {OMRP }}$ is not currently clear and further research on this important point is necessary. It would also be of interest to understand what special characteristics of this metal make it such a versatile system for 
CCT and whether other metal centers/coordination geometries might lead to equally efficient catalysts.

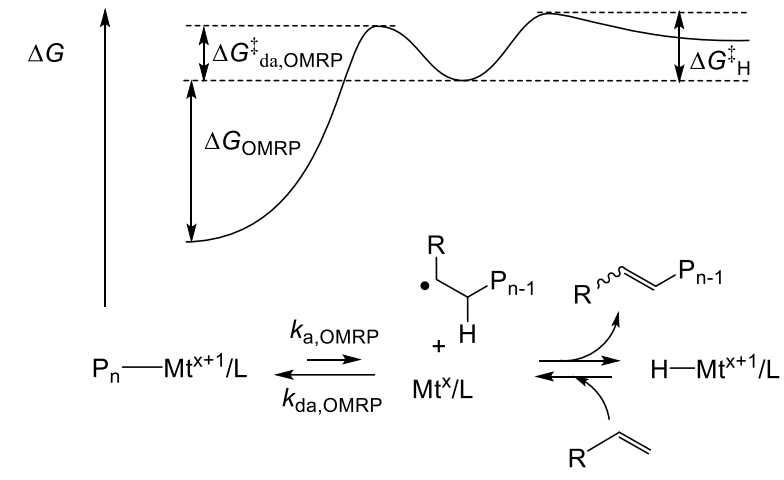

Figure 2. Interplay of OMRP and CCT processes.

Another interesting point concerns the possibility that CCT follows an alternative pathway by $\beta-\mathrm{H}$ elimination from the OMRP dormant species, see Scheme 3. The latter is common feature as a chain transfer pathway in insertion polymerization. This pathway was proposed to occur during the polymerization of styrene and methyl methacrylate (MMA) under ATRP conditions with a family of iron(II) a-diimine catalysts, $\left[\mathrm{FeCl}_{2}\left(\mathrm{R}^{1} \mathrm{~N}=\mathrm{CR}^{2}-\mathrm{R}^{2}=\mathrm{NR} \mathrm{R}^{1}\right)\right](6) \cdot{ }^{[24]}$ Depending on the nature of $R^{1}$ and $R^{2}$, this system leads to either controlled chain growth with the formation of targeted molecular weight, low dispersity $\left(\boxminus=M_{\mathrm{w}} / M_{\mathrm{n}}\right)$ polymers, or to short chains with the MW not evolving with conversion indicating CCT. Obviously, if OMRP and CCT compete and if OMRP interplays with ATRP, it is not surprising to witness CCT under ATRP conditions, as also reported earlier for a Mo system. ${ }^{[10]}$ System 6 is not capable of controlling the polymerization of styrene under OMRP conditions. However, the diaminobis(phenolato) Fe ${ }^{\text {Ill }}$ system 7, isoelectronic with the product of $\mathrm{Cl}$ transfer to $\mathbf{6}$, yields faster reverse ATRP with controlled chain growth and also OMRP trapping with no evidence for CCT. ${ }^{[11 \mathrm{e}, 11 \mathrm{f}]}$ Hence, Fe ${ }^{\text {III-C }}$ bond formation does not appear a prerequisite for CCT.

Indeed, a computational study has indicated that the preferred pathway to CCT, starting from the Fe ${ }^{\text {III }}$ OMRP dormant species, is homolytic bond breaking followed by direct $\mathrm{H}$ atom transfer (Scheme 3, path a), which occurs essentially without any overbarrier. ${ }^{[25]}$ For both $\alpha$-diimine and diaminobis(phenolato) systems (6 and 7), the Fe"l complex $\left(\mathrm{Mt}^{\times} / \mathrm{L}\right)$ has a 4-coordinate distorted tetrahedral structure and a high-spin state $(S=2)$, whereas the CCT intermediate $(H$ $\left.M t^{\mathrm{x}+1} / \mathrm{L}\right)$ and OMRP dormant species $\left(\mathrm{P}_{\mathrm{n}}-\mathrm{Mt}^{\mathrm{x}+1} / \mathrm{L}\right)$ have an $\mathrm{S}=$ $3 / 2$ ground state. Upon reacting with the organic radical $(S=$ $1 / 2$ ), both $\mathrm{H}$-atom transfer and direct trapping are spin-allowed processes on the spin quartet potential energy surface. The $\beta$ $\mathrm{H}$ elimination process from $\mathrm{P}_{\mathrm{n}}-\mathrm{Mt}^{\mathrm{x}+1} / \mathrm{L}$ (Scheme 3 , path $b$ ), on the other hand, needs a spin pairing to the doublet state in order to allow olefin coordination, but in fact an agostic alkyl isomer is energetically preferred (Scheme 4). A single-state $\beta$ $\mathrm{H}$ elimination pathway without olefin coordination was located, but the direct $\mathrm{H}$-atom transfer as in Scheme $3 a$ remains the preferred pathway. Thus, it appears that $\beta-\mathrm{H}$ elimination becomes a favored chain transfer pathway only for metal complexes with homolytically strong metal-carbon bonds such as the catalysts for insertion polymerization. (a)

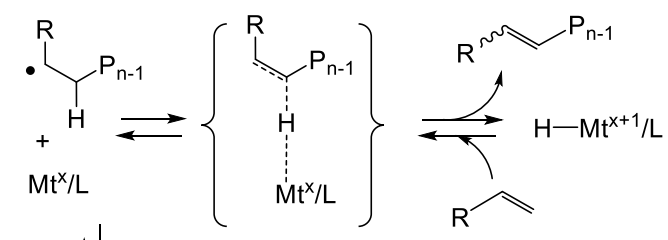

(b)

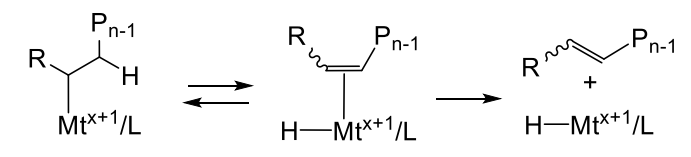

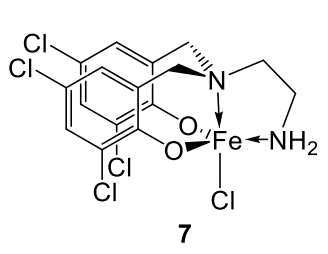

Scheme 3. CCT via either (a) direct $\beta-\mathrm{H}$ atom transfer or (b) OMRP trapping/ $\beta-\mathrm{H}$ elimination.

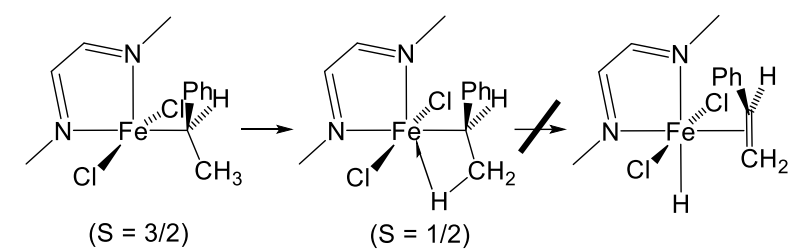

Scheme 4. Preferred structures for the alkyliron(III) systems $\left[\mathrm{FeCl}_{2}(\mathrm{CHMePh})(\mathrm{MeN}=\mathrm{CHCH}=\mathrm{NMe})\right]$.

\section{(d) With CRT.}

It has recently become evident that yet another process negatively interferes with OMRP controlled chain growth: catalyzed radical termination (CRT). ${ }^{[26]}$ The OMRP equilibrium efficiently suppresses spontaneous radical terminations, which have a second order rate dependence on free radical concentration, by storing the major portion of the radical chains in a latent form, $\mathrm{P}_{\mathrm{n}}-\mathrm{Mt}^{\mathrm{x}+1} / \mathrm{L}$. However, if the latter species is able to react with a second radical and if the resulting pathway leads to the collapse of the two radicals, rather than to the associative exchange pictured in Scheme $1 b$, the result will then be a radical termination rate with first order dependence in radical and in metal complex. Since the metal complex in the reduced state $\mathrm{Mt} \times / \mathrm{L}$ is regenerated, the overall process is 
catalytic. There are in principle two different ways in which CRT may occur, as shown in Scheme 5.

One possibility (inner cycle) consists of the addition of a second radical to the OMRP dormant species to yield an intermediate where two chains are bonded to the same metal center now formally in the oxidation state $x+2$. This is followed by reductive elimination to yield the saturated product of radical coupling. The other possibility (outer cycle) features addition of the second radical to the hydride CCT intermediate or direct $\mathrm{H}$ atom transfer to the radical chain, leading to the products of radical disproportionation. In that case, the radical chain can either add to the metal center in $\mathrm{H}-\mathrm{Mt}^{\mathrm{x}+1} / \mathrm{L}$ to yield a $(\mathrm{H})\left(\mathrm{P}_{\mathrm{m}}\right) \mathrm{Mt}^{\mathrm{t}+2} / \mathrm{L}$ intermediate or transition state, or directly abstract the $\mathrm{H}$ atom. The $\beta-\mathrm{H}$ elimination pathway to the CCT intermediate, which connects the inner with the outer cycle, has also been represented in Scheme 5 .

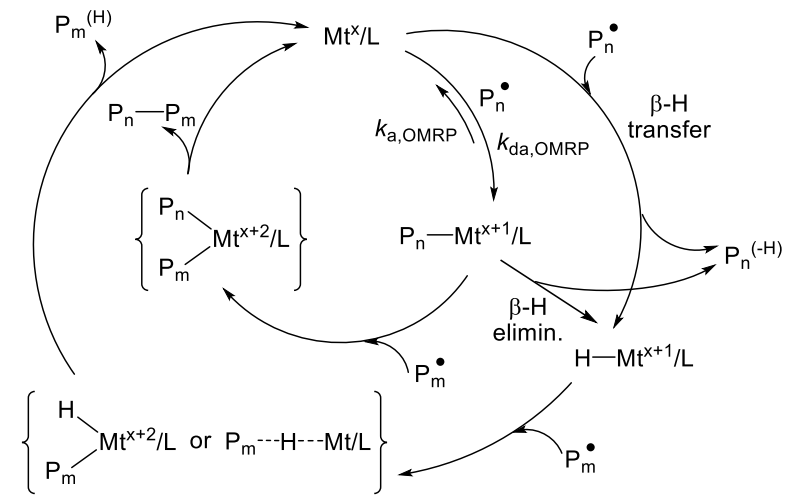

Scheme 5. Metal-catalyzed radical terminations.

The occurrence of CRT was first evidenced in a polymerization study of $n$-butyl acrylate $(n \mathrm{BuA})$ in the presence of a Cu' complex devoid of halogen atoms, $\left[\mathrm{Cu}\left(\mathrm{TPMA}^{*}\right)\right]^{+}\left[\mathrm{BF}_{4}\right]^{]}$ (8, Scheme 6), initiated by thermal decomposition of azobis(isobutyronitrile) (AIBN), i.e. typical OMRP conditions except for a substoichiometric amount of $\mathrm{Cu}$ complex relative to AIBN. Once all $\mathrm{Cu}^{\prime}$ is converted to the PnBA-Cull OMRP dormant species, excess radicals are expected to yield either conventional free radical polymerization or degenerative transfer OMRP (if fast associative radical exchange is allowed). In both cases, the polymerization rate should follow the kinetics of a fast free radical polymerization. In reality, the polymerization was significantly retarded by the metal complex, even after complete conversion of $\mathrm{Cu}^{\prime}$ to $\mathrm{PnBA}-\mathrm{Cu}^{\prime \prime}$; lower rates and lower molecular weight polymers were given by greater amounts of $\mathrm{Cu}$. These observations indicate that the rate of termination is increased relative to free radical polymerization and that the process continuously regenerates the $\mathrm{Cu}^{\prime}$ complex. ${ }^{[26]}$ Under ATRP-ICAR (initiator for continuous activator regeneration) conditions, the same complex gave fast and well controlled polymerization, showing that the ATRP equilibrium dominates the process.
In a subsequent ATRP study of methyl acrylate (MA) catalyzed by $[\mathrm{Cu}(\mathrm{TPMA})]^{+}(\mathbf{9})$ and $\left[\mathrm{Cu}\left(\mathrm{Me}_{6} \mathrm{TREN}\right)\right]^{+}(\mathbf{1 0}), \mathrm{CRT}$ was identified as the main cause for the significantly greater mole percentage of observed dead chains relative to the amount expected from spontaneous radical terminations. ${ }^{[27]}$ Further, it was found that the main termination mode is disproportionation with only a minor amount of coupling, whereas PMA radical chains favor coupling in conventional termination. This was taken as evidence that the preferred mechanism of CRT involves the CCT intermediate (outer cycle in Scheme 5). One important point concerns the relative CRT activity for acrylates and methacrylates. Methacrylates are more active monomers in Co-catalyzed CCT than acrylates because they are more susceptible to direct $\beta-\mathrm{H}$ transfer. ${ }^{[21 \mathrm{a}]}$ However, acrylates lead to more extensive CCT than methacrylates. ${ }^{[27]}$ This suggests that, for Cu-catalyzed CRT, the process is more likely to occur starting from the $\mathrm{P}_{\mathrm{n}}-\mathrm{Mt}^{\mathrm{x}+1} / \mathrm{L}$ dormant species, perhaps involving direct $\beta$ - $\mathrm{H}$ elimination or $\beta$ $\mathrm{H}$ transfer in a $\left\{\mathrm{P}_{\mathrm{n}} \mathrm{Mt}^{\mathrm{x}} / \mathrm{L}\right\}$ radical cage. In order to reduce the impact of CRT, when operating under ATRP conditions, it is sufficient to reduce the amount of $\mathrm{Mt}^{\mathrm{x}} / \mathrm{L}$ complex (as for instance in ARGET-ATRP or SARA-ATRP), since the effective polymerization rate depends only on the ratio between $[\mathrm{Mt} \times / L]$ and $\left[\mathrm{XMt}^{\mathrm{x}+1} / \mathrm{L}\right]$, whereas the rate of CRT is proportional to [Mt']. Reducing the impact of CRT under OMRP conditions, on the other hand, requires finding ways to block access to the hydride intermediate.

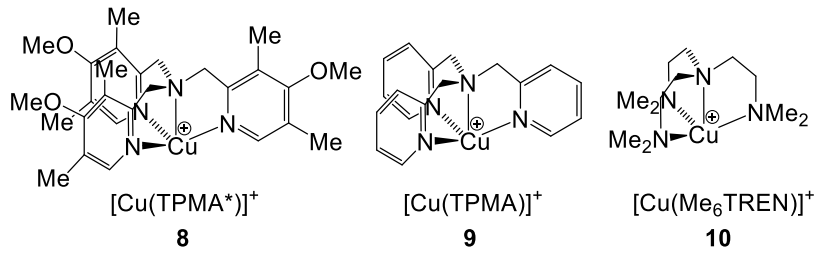

Scheme 6. Cu' complexes used for the study of CRT under OMRP or ATRP conditions.

The interesting question is why, under the same experimental conditions, $\mathrm{H}-\mathrm{Co}^{\prime \prime \prime}$ intermediates prefer to transfer the $\mathrm{H}$ atom to monomer leading to CCT rather than to other radicals leading to $\mathrm{CRT}$, whereas $\mathrm{H}-\mathrm{Cu}^{\text {ll }}$ intermediates show the opposite preference. This difference may be related to the different metal electronic configuration. The $\mathrm{H}-\mathrm{Co}^{\prime \prime \prime}$ intermediate is 5-coordinate (as for instance in $\mathrm{H}$ $\mathrm{Co}$ (porphyrin) or $\left.\mathrm{HCo}(\mathrm{acac})_{2}\right)$ and diamagnetic $(\mathrm{S}=0)$, whereas the $\mathrm{H}-\mathrm{Cu}$ ll system is also 5-coordinate but has one unpaired electron $(S=1 / 2)$. Hence, under the hypothesis of a radical addition to the metal in $H-M t^{x+1} / L$ to yield $(H)\left(P_{m}\right) M t^{x+2} / L$, there may be a lower energy barrier for a process leading to quenching two unpaired spins rather than one where the spin density shifts from the carbon atom to the metal atom (see Scheme 7). Stable square planar diamagnetic $\mathrm{Cu}^{\text {III }}$ complexes exist with certain ligand environments ${ }^{[28]}$ and the typical tetradentate ligands of Cu complexes (e.g. see Scheme 6) may adapt to this coordination environment through arm 
dissociation. $\mathrm{Co}^{\mathrm{IV}}$ is also rare but not unprecedented. ${ }^{[29]}$ If the process involves direct $\mathrm{H}$ atom abstraction by the radical chain, there may again be a lower barrier for a simple spin transfer in the Cu system than for the combined electron unpairing/pairing required for the Co system. The competing process of $\mathrm{H}$-atom transfer to monomer, leading to CCT, involves a spin density shift from metal to carbon in the case of copper, whereas the most efficient cobalt CCT catalysts (cobalt porphyrins and cobaloximes) involve separation of spins to produce the organic radical and a low spin $(S=1 / 2)$ Coll complex. A deeper analysis of the electronic structure will be necessary in order to fully understand the mechanism of these competing reactions.

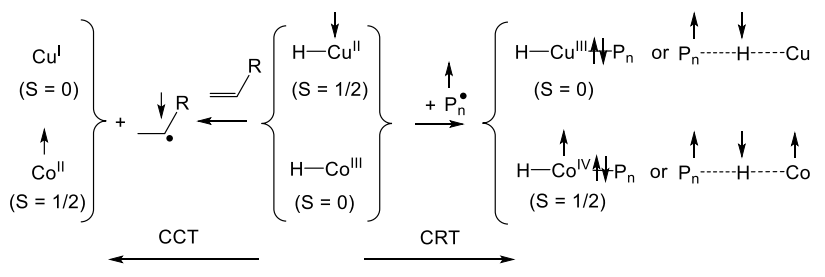

Scheme 7. Competing processes for $\mathrm{H}-\mathrm{Cu}^{\prime \prime}$ and $\mathrm{H}-\mathrm{Co}^{\text {III }}$ intermediates.

CRT is not restricted to copper complexes. Schroeder and Buback, using single pulse - pulsed laser polymerization EPR experiments, have shown that the rate of radical termination in $n$-butyl acrylate polymerization is greatly increased in the presence of $\mathrm{FeBr}_{2} / \mathrm{Br}$, which is a commonly used ATRP catalyst. This was evidenced by the rate of disappearance of the radical EPR signal after individual laser pulses, which became $1^{\text {st }}$ order in radicals in the presence of high Fe concentrations and the observed rate constant was first order in $\mathrm{Fe}$, indicating formation of the R-Fe"ll OMRP dormant species, but the Fe concentration remained constant after multiple pulses when the amount of generated radicals exceeded the metal stoichiometry, proving that the metal is not irreversibly consumed. ${ }^{[30]}$ The $\mathrm{FeBr}_{2} / \mathrm{Br}^{-}$system is an even better catalyst for the CRT of $n \mathrm{BA}\left[k_{\mathrm{t}}^{\mathrm{Fe}}\left(50^{\circ} \mathrm{C}\right)=1 \cdot 10^{5} \mathrm{~L} \cdot \mathrm{mol}^{-1} \cdot \mathrm{s}\right.$ $\left.{ }^{1}\right]$ than complex 9 , for which $k_{\mathrm{t}}^{\mathrm{Cu}}\left(40^{\circ} \mathrm{C}\right)=1.1 \cdot 10^{4} \mathrm{~L} \cdot \mathrm{mol}^{-1} \cdot \mathrm{s}^{-1}$. ${ }^{[27]}$ The radical termination of dodecyl methacrylate, on the other hand, is not efficiently catalyzed by $\mathrm{FeBl}_{2} / \mathrm{Br}^{-}\left(k_{\mathrm{t}}^{\mathrm{Fe}}\right.$ was found 3 orders of magnitude lower than in acrylate polymerization).

\section{Controlled polymerization of LAMs}

\section{(a) Challenges.}

The radical polymerization rate, as expresses by the propagation rate constant, roughly follows the monomer reactivity which is inversely proportional to that of the associated reactive function. Thus, less-active monomers (LAMs) are those associated to non-stabilized radicals such as simple olefins, halogenated olefins (vinyl chloride, vinylidene chloride, fluorinated olefins, etc.), vinyl ethers and vinyl acetate. The high radical reactivity introduces difficulties for controlling the polymerization at three levels: bond strength, sequence errors (for asymmetric monomers) and side reactions.

Stronger bonds with the trapping reagent in the dormant species $\mathrm{P}_{\mathrm{n}}-\mathrm{T}$ translate directly into harder activation (low $k_{\mathrm{a}}$ ) for reversible termination (RT) strategies. A special case is ATRP, where $P_{n}-X$ bond breaking is compensated by $P_{n}-M t$ bond formation, but as already discussed above ATRP is not expected to provide control for LAMs because of interplay with OMRP. There is no bond strength issue under a degenerative transfer (DT) approach because the controlling ability is only related to the associative exchange rate ( $k_{\text {exch }}$ in Scheme 1$)$, which does not correlate in principle with the BDE. Hence, DT strategies such as iodine transfer polymerization (ITP) or RAFT could potentially be suitable for any LAM. Indeed, promising results have been obtained in certain cases. However, DT techniques suffer, like also RT techniques, from inverted monomer additions and other interfering radical reactions.

In asymmetric MAM polymerization, there is a large kinetic preference for the product of "regular" (head-to-tail or HT) as opposed to "inverted" (head-to-head or $\mathrm{HH}$ ) addition, resulting in essentially no monomer sequence errors. Asymmetric LAMs, on the other hand, may lead to more frequent sequence errors with consequences on the dormant species reactivation. For instance, the primary radical following an $\mathrm{HH}$ addition to a monosubstituted monomer (Scheme 8), may yield a significantly stronger bond with the trapping reagent than the secondary radical formed by the HT addition. Hence, the polymerization may slow down or even stop as the $\mathrm{HH}$ dormant chains accumulate. DT techniques are also affected by this problem because exchange of the $\mathrm{HH}$ dormant chains with the more abundant HT radicals is no longer degenerate, therefore slower. Vinyl acetate is a typical monomer where $\mathrm{HH}$ addition was shown to lead to slowdown or blocking phenomena, whether using ATRP ${ }^{[31]}$ or degenerate transfer methods. ${ }^{[32]}$

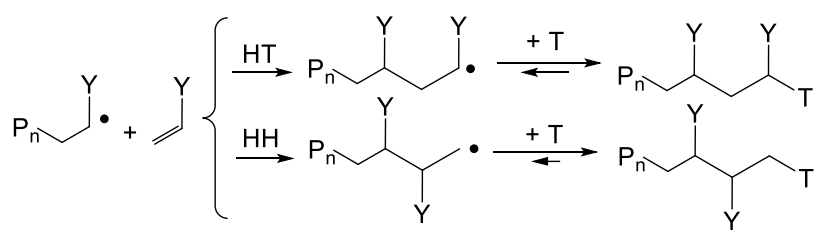

Scheme 8. Regular and inverted monomer addition for an asymmetric unsaturated monomer in radical polymerization.

The high radical reactivity leads to a potential number of unwanted side reactions. Chain transfer to solvent can of course be avoided by carrying out polymerization in the bulk monomer if possible. Chain transfer to polymer (back-biting) also affects free radical polymerization, particularly for ethylene. As this process is strongly temperature-dependent, better results are expected at lower temperatures. Monomers that have $\beta-\mathrm{H}$ atoms can suffer from degradative chain transfer to monomer, which constitutes a termination rather than a transfer event because the resulting allyl-type radical is too unreactive to add to the LAM. Here again, low temperature conditions are expected to help. Indeed, 
moderate success has been reported for the OMRP of ethylene and 1-octene near room temperature. ${ }^{[3]}$ Strong radicals may also attack the metal complex at one of the ligands rather than at the metal center. One obvious process is atom transfer with metal reduction, i.e. the radical deactivation step of ATRP. To avoid this, the metal complex should not contain halogen atoms or other easily transferrable groups. Another possibility is radical addition to a ligand, which is especially favored for ligands with noninnocent (i.e. redox-active) behavior. The reactivity of organic radicals with transition metal complexes have been recently reviewed. ${ }^{[15]}$ The appropriate design of the metal coordination sphere is crucial for successful OMRP in general and for the OMRP of LAMs in particular.

Finally, additional reactivity may result from the chain functional groups $Y$ of specific LAMs. Notably, a $Y$ group may be transferred to the metal atom, deactivating it. This reaction appears particularly accessible, at least on paper, following an $\mathrm{HH}$ addition, by $\beta-Y$ elimination with generation of a chain-end unsaturation, see Scheme 9 , which is mechanistically related to the $\beta-\mathrm{H}$ elimination as a pathway to CCT. This pathway has been evidenced for VAc with control by a $\mathrm{Cr}$ system (transfer of the acetate group, vide infra), ${ }^{[34]}$ but transfer of $\mathrm{Cl}$ from a growing poly(vinyl chloride) chain can also be easily imagined.

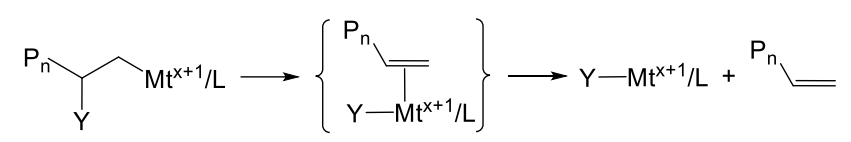

Scheme 9. Possible $\beta-Y$ group transfer from an OMRP HH dormant species.

\section{(b) OMRP of LAMs: need for homolytically weak metal-} carbon bonds.

The OMRP equilibrium is regulated by the metal-carbon bond dissociation energy (BDE), which must be weak under the RT approach. For instance, aiming at a system capable of building a chain with 100 monomer units in $1 \mathrm{~h}$, we need at least one activation event every 36 seconds if each activation leads to one monomer insertion or, roughly speaking, $k_{\mathrm{a}, \mathrm{OMRP}} \sim 0.03 \mathrm{~s}^{-1}$ requiring $\Delta G^{\ddagger}{ }_{\mathrm{a}, \mathrm{OMRP}} \sim 19 \mathrm{kcal} / \mathrm{mol}$. For good-control systems only a fraction of the activations events, say $10 \%$ or less, leads to a monomer insertion, in which case we need an activation event every $3.6 \mathrm{~s}$ or less, namely $k_{\mathrm{a}, \mathrm{OMRP}} \geq 0.3 \mathrm{~s}^{-1}$ or $\Delta G_{\mathrm{a}, \mathrm{OMRP}} \leq 18$ $\mathrm{kcal} / \mathrm{mol}$. Considering also that reactions where one molecule splits into two have a positive $T \Delta S_{\text {OMRP, }}$ maybe $4-6 \mathrm{kcal} / \mathrm{mol}$ in a condensed phase at $298 \mathrm{~K}$, and approximating $\Delta G_{\mathrm{a}, \mathrm{OMRP}}^{\ddagger} \sim$ $\Delta G_{\text {OMRP }}$, we need bonds with a BDE $<22-24 \mathrm{kcal} / \mathrm{mol}$ to have efficient polymerization, perhaps a bit higher for slower processes or for process that are activated at higher temperatures. These are very weak bonds! Consider for instance that the Co ${ }^{\text {III-Me bond }}$ strength in coenzyme B12, which functions through homolytic splitting, is $30-31 \mathrm{kcal} / \mathrm{mol}^{\left[{ }^{[35]}\right.}$

Systems suitable to control the polymerization of strong radicals (associated to LAMs) under the RT-OMRP approach must therefore be metals with a natural aptitude to yield weak bonds. In order to find inspiration in the literature, one must not look for systems with abundant and well-characterized alkyl derivatives but rather those for which alkyl derivatives are rare or only identified as unstable species. Metal-ligand bonds for the dblock elements generally get stronger upon descending a group from $3 \mathrm{~d}$ to $5 \mathrm{~d}$. Therefore, the most promising candidates for the OMRP of LAMs are the first transition series metals. Indeed, the only elements for which a successful OMRP of LAMs has been reported so far are cobalt, chromium, vanadium and iron. Heavier metals, notably Mo and Os, ${ }^{[10-11,36]}$ have also been successfully implemented in OMRP, but only for MAMs (mostly styrene).

Fine tuning the metal-carbon BDE within a certain limit is possible by modifying the steric bulk of the ligand substituents. This principle was demonstrated for the bis( $\beta$-diketonato)cobalt(II) system $^{[37]}$ and for a half-sandwich $\mathrm{Cr}^{\text {III }}$ system with diarylsubstituted $\beta$-diketiminato ligands. $\left.{ }^{[34,} 38\right]$ Therefore, upon appropriate choice of metal, coordination geometry, ligand type, steric encumbrance of the peripheral substituents and solvent (for systems allowing solvent coordination, e.g. see Scheme 2), it is conceivable to engineer metal complexes able to perform a successful RT-OMRP of any LAM.

\section{(c) OMRP of vinyl acetate (VAc).}

Vinyl acetate is undoubtedly the most investigated LAM, in large part because controlled architectures that include blocks of this monomers are highly desirable for many applications but also because it is a non-toxic liquid (b.p. $72.7^{\circ} \mathrm{C}$ ) that can be conveniently polymerized in regular glassware. It has therefore often be used as a model for other LAMs, such as vinyl chloride, which are often gaseous and/or hazardous. Furthermore, the resulting atactic poly(vinyl acetate) is soluble in many solvents and easy to characterize.

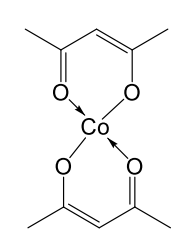

[Co(acac $\left.)_{2}\right], 11$

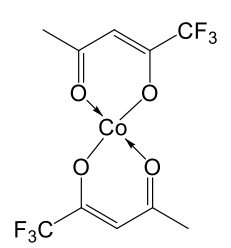

$\left[\mathrm{Co}(\mathrm{tfacac})_{2}\right], 12$<smiles></smiles>

[Co(hfacac) $)_{2}$ ], 13
$\left[\mathrm{Co}(\mathrm{tmhd})_{2}\right], 14$

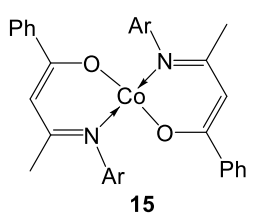

$\left(\mathrm{Ar}=\mathrm{Ph}, \mathrm{Xyl}, p-\mathrm{C}_{6} \mathrm{H}_{4} \mathrm{CF}_{3}\right)$

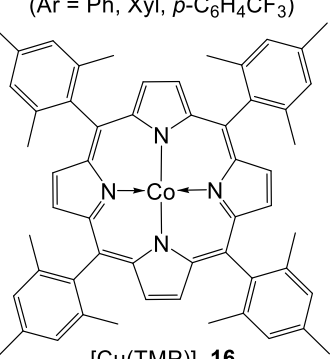

[Cu(TMP)], 16
Scheme 10. Cobalt complexes used for the OMRP of VAc.

Cobalt is the dominant element and the first one to be used in VAc polymerization controlled by OMRP. The first report made use of $\left[\mathrm{Co}(\mathrm{acac})_{2}\right](\mathbf{1 1}),{ }^{[16,39]}$ see Scheme 10. This compound remains to date the most versatile and promising system for controlling the polymerization of other LAMs (vide infra) by virtue of the absence of CRT and CCT. As already mentioned (Scheme 
2), it operates by the DT mechanism in bulk, but the RT pathway is activated and the DT is simultaneously blocked by the presence of monodentate ligands. A unimolecular initiator made up of small [Co(acac) $)_{2}$-capped oligomers ${ }^{[17]}$ (structure 1 in Scheme 2 with $n$ $\sim 4$ ) generally gives better results than $\left[\mathrm{Co}(\mathrm{acac})_{2}\right] / \mathrm{V} 70$ (V70 is an active diazo initiator that can be used under mild conditions: $t_{1 / 2}=$ $10 \mathrm{~h}$ at $30^{\circ} \mathrm{C}$ ). The modified trifluoromethylacetylacetonate (tfacac) complex $12^{[40]}$ containing an electron withdrawing $\mathrm{CF}_{3}$ group behaves in essentially the same way with an induction time in bulk indicating a DT mode. The effect of monodentate ligands has apparently not been studied. The hexafluoromethylacetylacetonate (hfacac) compound 13, on the other hand, is incapable of trapping the PVAc chains and yields uncontrolled polymerization. ${ }^{[40]}$ The 2,2,6,6-tetramethylheptanedionate (tmhd) complex $14^{[37]}$ also behaves like 11, but the increased steric bulk labilizes the Co-PVAc and Co-L bonds. Consequently, the system also works (slowly) in bulk in the RT mode and $L$ addition has a lesser effect on the RT mode than for [Co(acac) $)_{2}$ (see 5 in Scheme 2). Replacing one acac $O$ atom with an isolobal $\operatorname{ArN}$ donor to yield complexes with $\beta$-ketiminato ligands $(\mathbf{1 3})^{[41]}$ reduces the efficiency (slower trapping and presence of CCT). Complex [Co(TMP)] (TMP = tetramesitylporphyrin; 14) also controls the VAc polymerization, but only in the DT mode and there is slight interference of CCT. ${ }^{[42]}$

The strength of the Co $\mathrm{Co}^{\text {III-C}} \mathrm{C}$ bond is apparently rather sensitive to the ligand environment. Thus, nitrogen-rich ligands such as porphyrins $\left(\mathrm{N}_{4}\right)$ and glyoximes $\left(\mathrm{N}_{2} \mathrm{O}_{2}\right)$ provide relatively strong bonds; several stable R-Co"l'/L derivatives are known. These systems are suitable for the RT-OMRP of acrylates ${ }^{[9,19,43]}$ while PVAc radical trapping is irreversible, i.e. the Co-PVAc BDE is too high to yield RT activation. On the other hand, the $\mathrm{O}_{4}$ donor environment of bis(diketonates) allows control of VAc but the Co $\mathrm{CO}^{\text {III }}$ $\mathrm{C}$ bond is not sufficiently strong for a facile control of MAMs. For instance, special precautions were required to control the polymerization of $n$-butyl acrylate ${ }^{[44]}$ and acrylonitrile ${ }^{[45]}$ using 11, such as low temperatures, excess [ $\left.\mathrm{Co}(\mathrm{acac})_{2}\right]$, photochemical activation, and/or special additives. Allyl radicals are not trapped at all, therefore addition of a diene to $\left[\mathrm{Co}(\mathrm{acac})_{2}\right]$-capped polymers leads to efficient termination by allyl-allyl coupling. ${ }^{[46]}$ Stable R-CollI complexes with an $\mathrm{O}_{4}$ donor environment do not apparently exist.<smiles></smiles>

$\left[\mathrm{CpCr}\left(\right.\right.$ nacnac $\left.\left.^{\mathrm{Ar}, \mathrm{Ar}}\right)\right], 17$

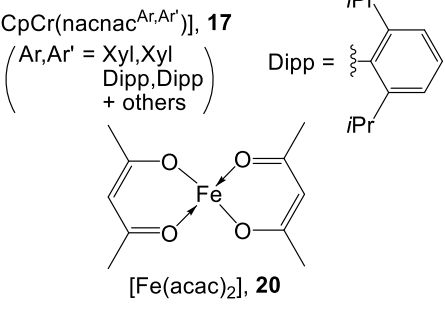

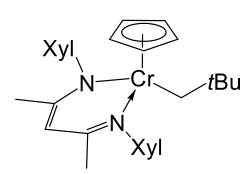

18

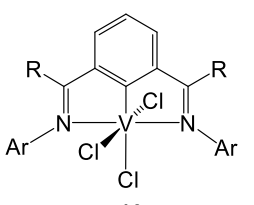

19
$\left(\begin{array}{l}\mathrm{R}=\mathrm{Me}, \mathrm{Et}, \mathrm{PPr} ; \mathrm{Ar}=\mathrm{Dipp} \\ + \text { others }\end{array}\right)$

Scheme 11. Complexes of other metals used for the OMRP of VAc.
Other metal systems (Scheme 11) have given less promising results than the above mentioned Co complexes but have highlighted a few interesting phenomena. Certain reactivity patterns observed for the $\left[\mathrm{CpCr}^{\prime \prime}\left(\right.\right.$ nacnac $\left.\left.^{\mathrm{Ar}, \mathrm{Ar}}\right)\right]$ systems (17) suggested a homolytically weak bond in $\left[\mathrm{CpCr}^{\prime \prime \prime}(\mathrm{R})\left(\right.\right.$ nacnac $\left.\left.^{\mathrm{Ar}, \mathrm{Ar}}\right)\right]$ and indeed VAc undergoes OMRP with 17/V70, the higher rate being observed for the bulkier Dipp,Dipp system. ${ }^{[34,38]}$ The best control resulted from use of $\left[\mathrm{CpCr}{ }^{\prime \prime \prime}\left(\mathrm{CH}_{2} \mathrm{CMe}_{3}\right)\right.$ (nacnac $\left.\left.{ }^{\mathrm{Xyl}, \mathrm{Xyl}}\right)\right]$ (18), a rare alkyl compound that is sufficiently stable to be isolated but sufficiently fragile to be thermally activated at room temperature, as a single-molecule initiator. However, a polymerization slowdown, attributed to head-to-head monomer additions, occurred after the first few hours and conversion did not exceed $14 \%$ after $400 \mathrm{~h}$, though yielding low $Đ$ polymers with targeted MW. Trying to reactivate these chains by warming resulted in total deactivation by formation of the acetate derivative $[\mathrm{CpCr}(\mathrm{OAc})$ (nacnac $\left.{ }^{X y 1, X y l}\right)$ (Scheme 12), which was isolated and characterized. This example highlights one additional danger for this particular monomer when using oxophilic metals with good affinity for the acetate ligand.

Vanadium complexes of type $\mathbf{1 9}^{[11 \mathrm{c}, 11 \mathrm{~d}, 47]}$ have also yielded controlled polymerization of VAc in combination with a radical source (AIBN, reverse ATRP conditions), but only upon warming to $120^{\circ}$, which requires work in sealed ampules and leads to catalyst death after ca. $6 \mathrm{~h}$, attributed to irreversible radical addition to the non-innocent diiminopyridine ligand. The best results were obtained with a sterically protected aryl group (Dipp) as $\mathrm{N}$ substituent and alkyl chains as imine carbon substituents. The proposed mechanism involves in situ reduction of the VIII complex by irreversible transfer of one $\mathrm{Cl}$ atom to the initiating radicals and generation of $\mathrm{V}^{\prime \prime}$, which then establishes the OMRP equilibrium. However, direct use of a pre-formed V" system gave poorer results. The organometallic dormant species was proposed to be stabilized by chelation, like for to the [ $\left.\mathrm{Co}(\mathrm{acac})_{2}\right]$ capped dormant species 1 .

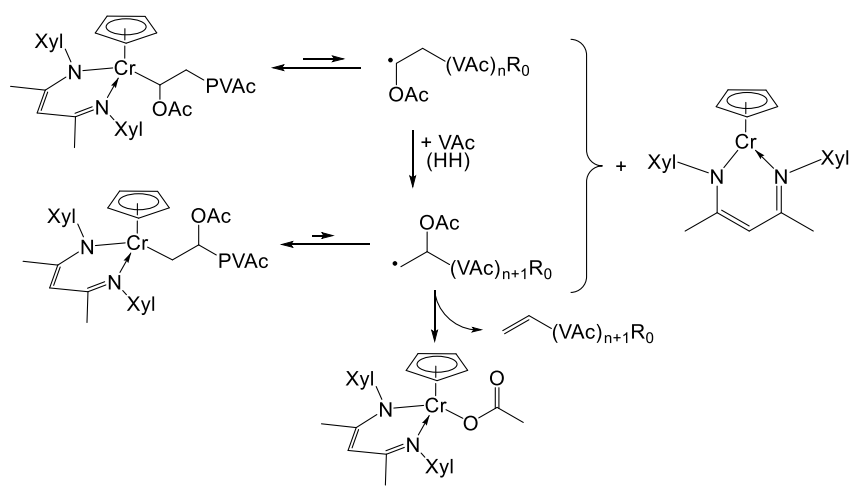

Scheme 12. Deactivation of the [CpCr(PVAc) $\left(\right.$ nacnac $\left.\left.^{\mathrm{Xy} l, X y l}\right)\right]$ dormant species after head-head $(\mathrm{HH})$ monomer addition.

Finally, VAc polymerization is also controlled by the iron acetylacetonate complex $\mathbf{2 0}^{[48]}$ under the same conditions as for the Co congener $\left(30^{\circ} \mathrm{C}\right.$, V70 initiator). The Fe-PVAc bond afforded by this system is weaker than the Co-PVAc bond in $\mathbf{1}$, 
because the polymerization also occurs under RT conditions (radical/Fe" $\leq 1)$. A low Fe efficiency $\left(M_{n, \text { obs }}>>M_{n, \text { calc }}\right)$, attributed to the presence of $\left[\mathrm{Fe}(\mathrm{acac})_{2}\right]_{\mathrm{n}}$ oligomers, is improved by dilution or by addition of ligands, $\mathrm{PMe}_{2} \mathrm{Ph}$ being the most effective one yielding polymers with $\Theta$ down to ca. 1.2 for $M_{n}$ up to 40000 . Contrary to the Co system, the addition of $L$ slows the polymerization down, indicating that the added $L$ stabilizes the Fe ${ }^{\text {III }}$ dormant species more than the trapping complex 20. This complex also controls the polymerization under DT conditions, with $M_{n}$ in better agreement with theory and $\Theta$ below 1.5 , but also with indication of CCT interference after returning to an $\mathrm{RT}$ regime at high conversions. One reason for the poorer performance of $\mathbf{2 0}$ relative to $\mathbf{1 1}$ is a slower radical trapping rate. Indeed, the synthesis of short $\mathrm{Fe}(\mathrm{acac})_{2}-(\mathrm{VAc})_{n} \mathrm{R}_{0}$ oligomers gave, under the same conditions, samples with an average $n>40 \mathrm{vs}$. ca. 4 for the $\mathrm{Co}$ analogue. The nature of the ligands around iron has the same effect on the Fe-C bond strength (stronger bonds for an $\mathrm{N}_{4}$ than for an $\mathrm{O}_{4}$ donor environment) as for cobalt, since iron phthalocyanine leads to irreversible PVAc trapping, whereas it yields well-controlled OMRP for styrene ${ }^{[49]}$.

\section{(d) OMRP of other LAMs.}

Extension of OMRP to other less active monomers (Scheme 13) has mostly involved $\mathbf{1 1}$ as controlling system. The polymerization of other vinyl esters has been reported for $\mathbf{1 1}$ (pivalate, benzoate ${ }^{[50]}$ and chloroacetate ${ }^{[51]}$ ) and 19 (propionate, pivalate, benzoate, laureate and stearate). ${ }^{[11 d, 47]}$ While esters of aliphatic acids are well-controlled like the acetate, the benzoate yields broader distributions with both 11 and 19.

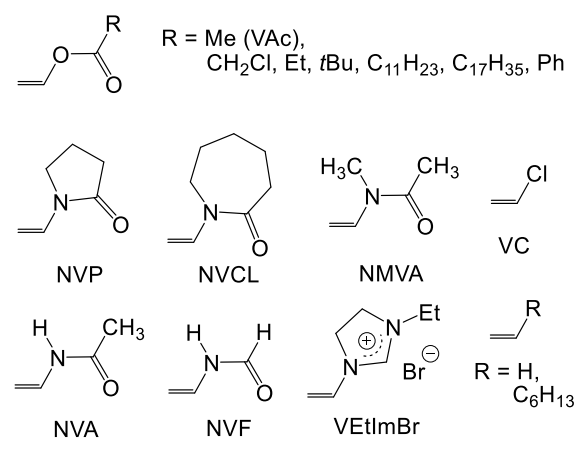

Scheme 13. LAMs investigated by OMRP

For vinyl amides, OMRP has apparently been explored only with 11. Investigated monomers include $\mathrm{N}$-vinylpyrrolidone (NVP) , ${ }^{[11-52]} \mathrm{N}$-vinylcaprolactam (NVCL) ${ }^{[52 c, 53]}$ and N-methyl-Nvinylacetamide (NMVA). ${ }^{[52 \mathrm{c}]}$ These monomers yield wellcontrolled polymerizations with rates in the order NVA > NVCL > NMVA. On the other hand, polymerization is too fast and uncontrolled for $\mathrm{N}$-vinylacetamide (NVA) and $\mathrm{N}$-vinylformamide $(\mathrm{NVF})$. Polymerizations were initiated by [Co(acac) $\left.)_{2}-(\mathrm{VAc}){ }_{4} \mathrm{R}_{0}\right]$ without additional radical source, thus the controlling mechanism is dissociative. For a rationalization of the peculiar effects of the monomer structure on the polymerization rate, see next section.
Vinyl chloride has also been controlled by OMRP using either $11 /$ V70 or the unimolecular [Co(acac) $)_{2}-(\mathrm{VAc})_{\sim 4} \mathrm{R}_{0}$ ] initiator. ${ }^{[54]} \mathrm{At}$ $40^{\circ} \mathrm{C}$, the polymerization stopped at low monomer conversion $(<10 \%)$, but sustained polymerization up to $34 \%$ conversion was realized under non-isothermal conditions with gradual warming up to $80^{\circ} \mathrm{C}$. This is suggestive of blocking by more strongly bonded $\mathrm{HH}$ dormant chains, which can only be reactivated at higher temperatures. DFT calculations supported this idea with an estimate of a stronger $\mathrm{Co}-\mathrm{C}$ bond in the $\mathrm{HH}$ dormant species by $4.8 \mathrm{kcal} / \mathrm{mol}$ relative to the HT species. Greater conversions were obtained also under isothermal conditions at $40^{\circ} \mathrm{C}$ by addition of water. The $M_{n}$ increased with monomer conversion but overall control was poor $(\Theta \sim 2)$ due to poor trapping of the regular HT chains and consequent free radical side reactions (chain transfer to monomer and to polymer). Better control $(\Theta<1.3)$ and targeted MW were obtained for a VC/VAc statistical copolymerization at $40^{\circ} \mathrm{C}$ yielding macromolecules with a 50:50 composition.

The unimolecular $\left[\mathrm{Co}(\mathrm{acac})_{2}-(\mathrm{VAc})_{\sim 4} \mathrm{R}_{0}\right]$ initiator has also been used to polymerize $\mathrm{N}$-vinyl-3-ethylimidazolium bromide (VEtImBr) with excellent control of MW and dispersity to yield an ionic liquid homopolymer as well as a block copolymer with VAc. ${ }^{[55]}$ Control was excellent when operating in methanol $(\theta$ 1.05), whereas faster polymerization and significant terminations by coupling were observed in DMF. This is another example of the solvent coordination effect on the dormant species activation, as previously demonstrated for VAc (Scheme 2).

As mentioned in a previous section, the $\left[\mathrm{Co}(\mathrm{acac})_{2}\right]$ system exerts a certain extent of control even for simple olefins (1-octene, ethylene). ${ }^{[33,56]}$ Statistical VAc/olefin copolymers were well controlled, but 1-octene homopolymerization from a PVAc$\mathrm{Co}(\mathrm{acac})_{2}$ macroinitiator yields only short chains (D.P. $\left.=4\right)$ before termination, presumably by degradative chain transfer. ${ }^{[33]}$ This result, however, shows that even the stronger bond with secondary and primary (for ethylene) alkyls can be reactivated for [RCo'II'(acac $)_{2}$ ]. In DFT calculations of the BDE for various [RCo'l'(acac) $)_{2}$ compounds, the bond to $\mathrm{CH}_{3}$ (model of a PE chain) was estimated as $8.8 \mathrm{kcal} / \mathrm{mol}$ stronger than that to $\mathrm{CH}\left(\mathrm{CH}_{3}\right) \mathrm{OOCCH}_{3}$ (model of a PVAc chain) and $16.0 \mathrm{kcal} / \mathrm{mol}$ stronger than that to $\mathrm{CH}\left(\mathrm{CH}_{3}\right) \mathrm{COOCH}_{3}$ (model of a PMA chain). ${ }^{[17]}$

\section{(e) The importance of chelation.}

In this final part I wish to highlight the consequences of secondary coordination by chain functional groups (chelation) in the dormant species on controlled polymerization with two recent studies on vinyl amide and vinyl acetate OMRP controlled by $\mathbf{1 1}$. Carbonyl containing monomers are not sufficiently strong donors as free molecules to provide significant ligand stabilization to either the $\left[\mathrm{P}_{\mathrm{n}} \mathrm{Co}(\mathrm{acac})_{2}\right]$ dormant species or [Co(acac $\left.)_{2}\right]$ (Scheme 2). However, the chelate effect makes the formation of a 5membered ring sufficiently stabilizing, by ca. $3 \mathrm{kcal} / \mathrm{mol}$ for $\mathrm{VAc}^{[18 \mathrm{~b}]}$ and up to $7.8 \mathrm{kcal} / \mathrm{mol}$ for NVMA ${ }^{[52 \mathrm{c}]}$ according to DFT calculations. Radical dissociation from the 6-coordinate octahedral dormant species therefore involves two steps, each one requiring energy input (Figure 3 ): chelate opening to a 5coordinate square pyramidal geometry with a monodentate alkyl 
chain (strength of chelation, $\Delta G_{\text {chel }}$ ), and homolytic bond cleavage to yield tetrahedral [ $\mathrm{Co}(\mathrm{acac})_{2}$ ] plus free radical (intrinsic bond strength, $\Delta G_{\text {(o-C) }}$.

The relative polymerization rates of NVP, NVCL and NMVA do not seem related to differences in propagation rate constant, $k_{\text {p }}$. DFT calculations have shown that $\Delta G_{\text {Co-c }}$ is relatively similar for the three dormant species, but $\Delta G_{\text {chel }}$ increases on going from NVP to NVCL and then further to NVMA (Scheme 14), because the ring strain in the two lactams reduces the carbonyl donor power, particularly for the more strained NVP system. In case of the secondary amides, the $\mathrm{N}-\mathrm{H}$ bond and the $\mathrm{C}=\mathrm{O}$ functions can engage in $\mathrm{H}$-bonding as proton donor and acceptor, respectively. Chelation removes the $\mathrm{H}$-bond acceptor ability of the radical $\mathrm{CO}$ group, whereas this is maintained in the open form. As a result, chelation no longer provides extra stabilization to the dormant species, which becomes insufficiently stabilized for OMRP control. ${ }^{[52 c]}$

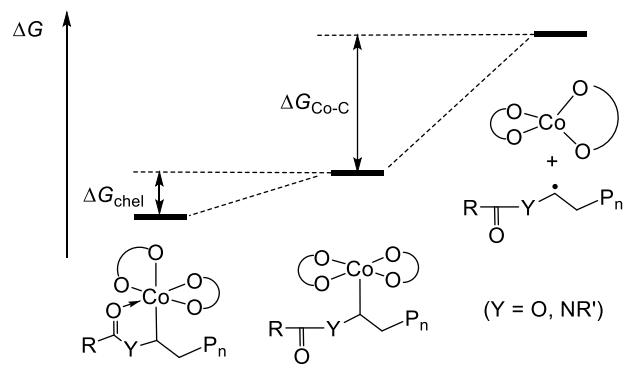

Figure 3. Two-step dissociative activation of chelated dormant species.

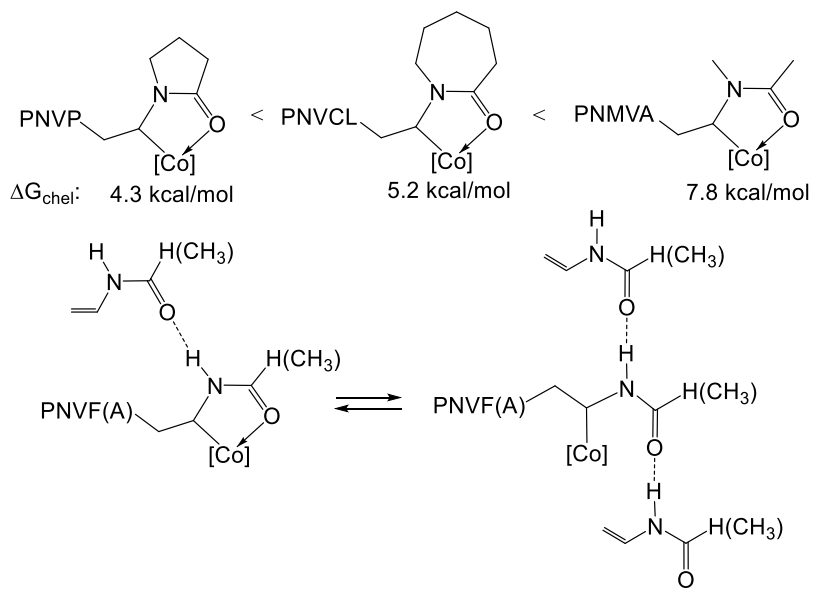

Scheme 14. Effect of chelation on the dormant species stabilization for vinyl amides.

Concerning vinyl acetate, one question of interest was to understand why there is no slowdown when the polymerization is controlled by $\mathbf{1 1}$ (first order kinetics and good control up to D.P. above 1500), contrary to all other known methods, including OMRP with the chromium system 18 (vide supra). Two possible ways to rationalize this behavior are that either $(I)$ system 11 somehow decreases the incidence of $\mathrm{HH}$ monomer additions or (ii) the $\mathrm{HH}$ dormant species is reactivated at a similar rate as the regular HT species. A detailed NMR investigation of the polymer could exclude hypothesis ( $I$ ) and confirm (ii): the same level of monomer inversions is observed with and without $\mathbf{1 1}$ and there is no accumulation of [ $\left.\mathrm{Co}(\mathrm{acac})_{2}\right]$-capped chains with a $\mathrm{HH}$ w end. DFT calculations gave support to hypothesis (ii) and provided understanding: while $\Delta G_{\mathrm{Co}-\mathrm{C}}$ is indeed greater for the $\mathrm{HH}$ species (ca. $5 \mathrm{kcal} / \mathrm{mol}$ higher that the HT species), this type of monomer sequence induces formation of a less stable 6-member chelate (lower $\Delta G_{\text {chel }}$ ); compensation of the two effects yields similar activation enthalpies (difference of only $1 \mathrm{kcal} / \mathrm{mol}$ ), see Figure 4. ${ }^{[57]}$ Incidentally, the calculations also confirmed the substantial difference of bond energy between the $\mathrm{HH}$ and $\mathrm{HT}$ forms in the dormant species obtained with other controlling methods.

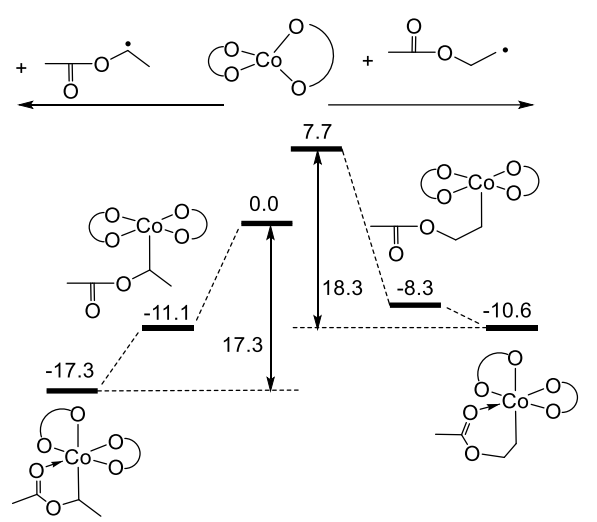

Figure 4. Enthalpic balance of Co-C bond formation and chelation for the HT and $\mathrm{HH}$ chain ends in the $\left[\mathrm{Co}(\mathrm{acac})_{2}\right]$-capped PVAc dormant species (values in $\mathrm{kcal} / \mathrm{mol})$.

\section{Summary and Perspectives}

I have highlighted the considerable success of OMRP for the controlled polymerization of a few less active monomers and the reasons for such success. These are in large part related to access to weak metal-carbon bonds, even for the most reactive radicals, through a choice of metal, ligands, coordination environment, steric bulk of the ligand periphery, and solvent for metal complexes with available coordination sites. Another key factor for controllability of specific monomers (vinyl esters and amides) is chelation by the dormant chain end. In addition, OMRP can operate under both the RT and DT modes, the latter being free from constraints of metal-bond strengths and suffering only from bond strength differences between the $\mathrm{HH}$ and $\mathrm{HT}$ dormant species. ATRP does not offer all these advantages because the metal interacts only with the halogen atom, thus it can influence the moderating equilibrium only through the metal-halogen bond strength, which is related to the metal redox properties and halidophilicity. Furthermore, ATRP is contaminated by the OMRP equilibrium, to an extent that depends on the metal complex nature and on the radical reactivity, opening the way to CRT. In the end, we must always worry about OMRP when doing ATRP 
of less active monomers, thus selecting an OMRP operating mode in the first place using halogen free systems is simpler.

OMRP has also drawbacks, however. One is CRT, a phenomenon discovered only very recently and still poorly understood. ${ }^{[26]}$ A second one is CCT, which however may also affect ATRP. The two appear to share the common hydride intermediate, $\mathrm{HMt}^{\mathrm{x}+1} / \mathrm{L}$. There is at the moment no clear understanding of how the nature of the metal/coordination sphere and the radical structure and reactivity determine access to the $\mathrm{HMt}^{\mathrm{x}+1} / \mathrm{L}$ intermediate and to a discrimination between CCT and CRT. The intimate mechanism of CRT and how to operate on the coordination sphere to block this pathway are also unclear: does the cycle start with $\beta-\mathrm{H}$ transfer as in CCT or does $\beta-\mathrm{H}$ elimination from the OMRP dormant species occur? Is catalyzed coupling possible? Is the metal spin configuration a key to discriminate between CRT and CCT?

So far CRT has only been highlighted for $\mathrm{Cu}^{\prime}$ complexes with $\mathrm{N}_{4}$-type ligands that impose a trigonal pyramidal structure ${ }^{[26-27]}$ and for a Fe" halide system, ${ }^{[30]}$ working in each case with acrylate monomers. On the other hand, the diaminebis(phenolate) $\mathrm{Fe}$ complex 7 (Scheme 3) gives well-controlled styrene and MMA polymerizations under reverse ATRP conditions ${ }^{[11 e, 11 f]}$ with active involvement of OMRP (for styrene) ) $^{[11 \mathrm{~g}]}$ and no observed involvement of CCT or CRT. Acrylates, however, are not controlled by this system. ${ }^{[11 f]}$ Also, system 6 yields good control for styrene, MMA and also MA under ATRP conditions for specific diimine substituents, but leads to CCT for styrene and MMA with other diimines, therefore the HFe"II intermediate afforded by this system prefers to transfer $\mathrm{H}$ to monomer, ${ }^{[24]}$ whereas that afforded by $\mathrm{FeBr}_{2} / \mathrm{Br}$ prefers to deliver the $\mathrm{H}$ atom to another radical (for the $n B A$ polymerization). OMRP with complex 20 (Scheme 11) has also imparted some control to VAc polymerization without any clear evidence of CRT, although there is some CCT activity.

The above examples underline a rather complex mechanistic interplay for iron. More detailed mechanistic investigations of $\mathrm{Fe}$ systems as a function of coordination sphere and monomer is warranted because iron is very attractive for controlled radical polymerization, ${ }^{[58]}$ especially in an OMRP mode where the metal atom remains as chain cap in the isolated polymer. Indeed, the stoichiometric nature of the metal complex (one metal per chain) is another drawback of OMRP. Ultimately, implementation of OMRP at the production scale must take into account the cost of the metal complex and the cost of its removal from the polymer chain end, since the metal presence in the polymer is not desired for most applications. Thus, ligands should ideally be simple and inexpensive. In addition, since traces of metal may contaminate the purified polymer, non-toxic metals such as iron present greater interest.

Copper is also a potentially attractive metal for OMRP of less active monomers, because of the paucity of stable $\mathrm{Cu}^{\text {ll }}$ alkyl derivatives in the literature, hence sufficiently labile bonds with strong radicals should result. Many $\mathrm{Cu}^{\prime}$ and $\mathrm{Cu}^{\prime \prime}$ complexes have been developed, generally in combination with halide ligands, in order to improve ATRP activity. New halide-free complexes will need to be developed and tested for the OMRP of LAMs, with specific attention to CCT and CRT. Attention to other metals in the first transition series that have so far been neglected for the OMRP of LAMs (e.g. manganese, nickel) and further study of those that have only been briefly investigated (vanadium, chromium and of course iron) can certainly be rewarding.

Another area of promising development concerns other challenging LAMs. There are many more monomers available than those already investigated by OMRP (Scheme 13) and their polymers are of strong interest if the chain length, dispersity and chain end functionality can be controlled. One example is the family of fluorinated monomers such as vinylidene fluoride, trifluoro- and tetrafluoroethylene, and mixed fluorochloroolefins. For some of these, the polymerization has been controlled reasonably well by ITP, ${ }^{[59]}$ but the use of OMRP may prove advantageous in terms of controlling quality and macromolecular engineering. Another interesting family is the vinyl ethers, for which homopolymers are easily controlled by cationic living polymerization, ${ }^{60]}$ but many copolymers, especially alternating ones, with different functionalized monomers including other LAMs are commonly obtained by radical methods.

\section{Acknowledgements}

I am grateful to the Centre National de la Recherche Scientifique (CNRS), to the Institut Universitaire de France (IUF) and to the Agence Nationale de la Recherche (ANR, grant no. ANR-14CE07-0012-01 "FLUPOL") for financial support. Our computational research was granted access to the HPC resources of CINES under the allocation 086343 made by GENCI (Grand Equipement National de Calcul Intensif) and to the resources of the CICT (Centre Interuniversitaire de Calcul de Toulouse, project CALMIP).

Keywords: OMRP • Controlled radical polymerization - Metalcarbon bond strength $\cdot$ ATRP $\cdot$ Less reactive monomer

[1] Chem. Eng. News 1980, 58(40), 28-33.

[2] K. Matyjaszewski, Y. Gnanou, L. Leibler, Macromolecular Engineering: Precise Synthesis, Materials Properties, Applications, Wiley-VCH Verlag $\mathrm{GmbH}, 2007$.

[3] A. D. Jenkins, R. G. Jones, G. Moad, Pure Appl. Chem. 2010, 82, 483491.

[4] a) C. J. Hawker, A. W. Bosman, E. Harth, Chem. Rev. 2001, 101, 3661 3688. b) R. B. Grubbs, Polym. Rev. 2011, 51, 104-137. c) J. Nicolas, Y Guillaneuf, C. Lefay, D. Bertin, D. Gigmes, B. Charleux, Progr. Polym. Sci. 2013, 38, 63-235.

[5] a) E. Rizzardo, J. Chiefari, R. Mayadunne, G. Moad, S. Thang, Macromol. Symp. 2001, 174, 209-212. b) G. Moad, E. Rizzardo, S. H. Thang, Austr J. Chem. 2005, 58, 379-410. c) G. Moad, E. Rizzardo, S. H. Thang, Polymer 2008, 49, 1079-1131. d) M. Destarac, Polym. Rev. 2011, 51, 163-187.

[6] a) R. Poli, in Polymer Science: A Comprehensive Reference, Vol. 3 (Eds.: K. Matyjaszewski, M. Möller), Elsevier BV, Amsterdam, 2012, pp. 351-375. b) K. M. Smith, W. S. McNeil, A. S. Abd-El-Aziz, Macromol. Chem. Phys. 2010, 211, 10-16. c) L. E. N. Allan, M. R. Perry, M. P Shaver, Progr. Polym. Sci. 2012, 37, 127-156. 
[7] a) K. Matyjaszewski, J. H. Xia, Chem. Rev. 2001, 101, 2921-2990. b) M. Kamigaito, T. Ando, M. Sawamoto, Chem. Rev. 2001, 101, 3689-3745. c) M. Ouchi, T. Terashima, M. Sawamoto, Chem. Rev. 2009, 109, 4963 5050. d) F. di Lena, K. Matyjaszewski, Progr. Polym. Sci. 2010, 35, 959 1021.

[8] a) J.-S. Wang, K. Matyjaszewski, J. Am. Chem. Soc. 1995, 117, 56145615. b) M. Kato, M. Kamigaito, M. Sawamoto, T. Higashimura, Macromolecules 1995, 28, 1721-1723.

[9] a) B. B. Wayland, G. Poszmik, S. Mukerjee, J. Am. Chem. Soc. 1994, 116, 7943-7944. b) L. D. Arvanatitopoulos, M. P. Greuel, H. J. Harwood, Polym. Prep. 1994, 35, 549-550.

[10] E. Le Grognec, J. Claverie, R. Poli, J. Am. Chem. Soc. 2001, 123, 9513 9524.

[11] a) W. A. Braunecker, W. C. Brown, B. Morelli, W. Tang, R. Poli, K. Matyjaszewski, Macromolecules 2007, 40, 8576-8585. b) Y. Champouret K. C. MacLeod, K. M. Smith, R. Poli, Organometallics 2010, 29, 31253132. c) M. P. Shaver, M. E. Hanhan, M. R. Jones, Chem. Commun 2010, 46, 2127-2129. d) L. E. N. Allan, E. D. Cross, T. W. FrancisPranger, M. E. Hanhan, M. R. Jones, J. K. Pearson, M. R. Perry, T. Storr, M. P. Shaver, Macromolecules 2011, 44, 4072-4081. e) L. E. N. Allan, J. P. MacDonald, A. M. Reckling, C. M. Kozak, M. P. Shaver, Macromol. Rapid Comm. 2012, 33, 414-418. f) L. E. N. Allan, J. P. MacDonald, G. S. Nichol, M. P. Shaver, Macromolecules 2014, 47, 1249-1257. g) R. Poli, M. P. Shaver, Inorg. Chem. 2014, 53, 7580-7590.

[12] K. Matyjaszewski, B. E. Woodworth, Macromolecules 1998, 31, 47184723.

[13] R. Poli, Angew. Chem., Int. Ed. 2006, 45, 5058-5070.

[14] M. B. Gillies, K. Matyjaszewski, P.-O. Norrby, T. Pintauer, R. Poli, P. Richard, Macromolecules 2003, 36, 8551-8559.

[15] R. Poli, Eur. J. Inorg. Chem. 2011, 1513-1530.

[16] A. Debuigne, J. R. Caille, R. Jérôme, Angew. Chem., Int. Ed. 2005, 44, 1101-1104.

[17] A. Debuigne, Y. Champouret, R. Jérôme, R. Poli, C. Detrembleur, Chem. Eur. J. 2008, 14, 4046-4059.

[18] a) S. Maria, H. Kaneyoshi, K. Matyjaszewski, R. Poli, Chem. Eur. J. 2007, 13, 2480-2492. b) A. Debuigne, R. Poli, R. Jérôme, C. Jérôme, C. Detrembleur, ACS Symp. Ser. 2009, 1024, 131-148.

[19] Z. Lu, M. Fryd, B. B. Wayland, Macromolecules 2004, 37, 2686-2687.

[20] a) N. S. Enikolopov, G. V. Korolev, A. P. Marchenko, G. V. Ponomarev, B. R. Smirnov, V. I. Titov, Russian Pat. 664434, Feb 25, 1980. b) B. R Smirnov, I. M. Bel'govskii, G. V. Ponomarev, A. P. Marchenko, N. S. Enikolopian, Dokl. Akad. Nauk. SSSR 1980, 254, 127-130. c) N. S. Enikolopyan, B. R. Smirnov, G. V. Ponomarev, I. M. Belgovskii, J. Polym. Sci., Polym. Chem. 1981, 19, 879-889. d) B. R. Smirnov, A. P. Marchenko, G. V. Korolev, I. M. Belgovskii, N. S. Yenikolopyan, Vysokomol. Soedin., Ser. A 1981, 23, 1042-1050.

[21] a) A. A. Gridnev, S. D. Ittel, Chem. Rev. 2001, 101, 3611-3659. b) J. P. A. Heuts, N. M. B. Smeets, Polym. Chem. 2011, 2, 2407-2423.

[22] A. Rahman, W. G. Jackson, A. C. Willis, A. D. Rae, Chem. Commun. 2003, 2748-2749.

[23] A. Debuigne, R. Poli, C. Jérôme, R. Jérome, C. Detrembleur, Prog Polym. Sci. 2009, 34, 211-239.

[24] a) M. P. Shaver, L. E. N. Allan, H. S. Rzepa, V. C. Gibson, Angew. Chem. Int. Ed. Eng. 2006, 45, 1241-1244. b) L. E. N. Allan, M. P. Shaver, A. J. P. White, V. C. Gibson, Inorg. Chem. 2007, 46, 8963-8970. c) R. K. O'Reilly, M. P. Shaver, V. C. Gibson, A. J. P. White, Macromolecules 2007, 40, 7441-7452. d) M. P. Shaver, L. E. N. Allan, V. C. Gibson, Organometallics 2007, 26, 4725-4730.

[25] R. Poli, M. P. Shaver, Chem. Eur. J. 2014, 20, 17530-17540.

[26] K. Schröder, D. Konkolewicz, R. Poli, K. Matyjaszewski, Organometallics 2012, 31, 7994-7999.

[27] Y. Wang, N. Soerensen, M. Zhong, H. Schroeder, M. Buback, K. Matyjaszewski, Macromolecules 2013, 46, 683-691.

[28] a) D. Naumann, T. Roy, B. Caeners, D. Hutten, K. F. Tebbe, T. Gilles, Z. Anorg. Allg. Chem. 2000, 626, 999-1003. b) G. Hogarth, A. Pateman, S.
P. Redmond, Inorg. Chim. Acta 2000, 306, 232-236. c) G. Hogarth, E. Rainford-Brent, I. Richards, Inorg. Chim. Acta 2009, 362, 1361-1364.

[29] a) B. K. Bower, H. G. Tennent, J. Am. Chem. Soc. 1972, 94, 2512-2514 b) J. Topich, J. Halpern, Inorg. Chem. 1979, 18, 1339-1343. c) R. Guilard, F. Burdet, J.-M. Barbe, C. P. Gros, E. Espinosa, J. Shao, Z. Ou, R. Zhan, K. M. Kadish, Inorg. Chem. 2005, 44, 3972-3983.

[30] H. Schroeder, M. Buback, Macromolecules 2014, 47, 6645-6651.

[31] a) J. Xia, H.-j. Paik, K. Matyjaszewski, Macromolecules 1999, 32, 83108314. b) M. Wakioka, K. Y. Baek, T. Ando, M. Kamigaito, M. Sawamoto, Macromolecules 2002, 35, 330-333.

[32] a) M. Destarac, D. Charmot, X. Franck, S. Z. Zard, Macromol. Rapid Comm. 2000, 21, 1035-1039. b) M. H. Stenzel, L. Cummins, G. E. Roberts, T. P. Davis, P. Vana, C. Barner-Kowollik, Macromol. Chem. Phys. 2003, 204, 1160-1168. c) M. C. lovu, K. Matyjaszewski, Macromolecules 2003, 36, 9346-9354. d) Y. Kwak, A. Goto, T. Fukuda, Y. Kobayashi, S. Yamago, Macromolecules 2006, 39, 4671-4679. e) A. Postma, T. P. Davis, G. X. Li, G. Moad, M. S. O'Shea, Macromolecules 2006, 39, 5307-5318.

[33] R. Bryaskova, N. Willet, P. Degee, P. Dubois, R. Jerome, C. Detrembleur, J. Polym. Sci., Part A: Polym. Chem. 2007, 45, 2532-2542.

[34] Y. Champouret, K. C. MacLeod, U. Baisch, B. O. Patrick, K. M. Smith, R Poli, Organometallics 2010, 29, 167-176.

[35] a) B. P. Hay, R. G. Finke, J. Am. Chem. Soc. 1986, 108, 4820-4829. b) L. B. Luo, G. Li, H. L. Chen, S. W. Fu, S. Y. Zhang, J. Chem. Soc., Dalton Trans. 1998, 2103-2107.

[36] a) F. Stoffelbach, R. Poli, P. Richard, J. Organometal. Chem. 2002, 663, 269-276. b) F. Stoffelbach, R. Poli, S. Maria, P. Richard, J. Organomet Chem 2007, 692, 3133-3143.

[37] K. S. Santhosh Kumar, Y. Gnanou, Y. Champouret, J.-C. Daran, R. Poli, Chem. Eur. J. 2009, 15, 4874-4885.

[38] Y. Champouret, U. Baisch, R. Poli, L. Tang, J. L. Conway, K. M. Smith, Angew. Chem., Int. Ed. 2008, 47, 6069-6072.

[39] a) A. Debuigne, J. R. Caille, C. Detrembleur, R. Jerome, Angew. Chem. Int. Ed. 2005, 44, 3439-3442. b) A. Debuigne, J. R. Caille, N. Willet, R Jerome, Macromolecules 2005, 38, 9488-9496. c) A. Debuigne, J.-R Caille, R. Jérôme, Macromolecules 2005, 38, 5452-5458. d) R. Bryaskova, C. Detrembleur, A. Debuigne, R. Jerome, Macromolecules 2006, 39, 8263-8268. e) R. Bryaskova, N. Willet, A. Debuigne, R. Jerome, C. Detrembleur, J. Polym. Sci., Part A: Polym. Chem. 2006, 45, 81-89. f) C. Detrembleur, A. Debuigne, R. Bryaskova, B. Charleux, R. Jerome, Macromol. Rapid Comm. 2006, 27, 37-41. g) C. Detrembleur, O. Stoilova, R. Bryaskova, A. Debuigne, A. Mouithys-Mickalad, R. Jerome, Macromol. Rapid Commun. 2006, 27, 498-504. h) V. Sciannamea, A. Debuigne, Y. Piette, R. Jerome, C. Detrembleur, Chem. Commun. 2006, 4180-4182.

[40] H. Kaneyoshi, K. Matyjaszewski, Macromolecules 2005, 38, 8163-8169.

[41] K. S. Santhosh Kumar, Y. Li, Y. Gnanou, U. Baisch, Y. Champouret, R. Poli, K. C. D. Robson, W. S. McNeil, Chem. Asian J. 2009, 4, 1257-1265.

[42] C. H. Peng, J. Scricco, S. Li, M. Fryd, B. B. Wayland, Macromolecules 2008, 41, 2368-2373.

[43] B. B. Wayland, L. Basickes, S. Mukerjee, M. Wei, M. Fryd, Macromolecules 1997, 30, 8109 - 8112.

[44] a) M. Hurtgen, A. Debuigne, C. Jerome, C. Detrembleur, Macromolecules 2010, 43, 886-894. b) C. Detrembleur, D. L. Versace, Y. Piette, M. Hurtgen, C. Jerome, J. Lalevee, A. Debuigne, Polym. Chem. 2012, 3, 1856-1866.

[45] a) A. Debuigne, C. Michaux, C. Jérôme, R. Jérôme, R. Poli, C Detrembleur, Chem. Eur. J. 2008, 14, 7623-7637. b) A. Debuigne, J. Warnant, R. Jerome, I. Voets, A. de Keizer, M. A. Stuart, C. Detrembleur Macromolecules 2008, 41, 2353-2360.

[46] a) A. Debuigne, C. Jerome, C. Detrembleur, Angew. Chem. Engl. 2009 48, 1422-1424. b) A. Debuigne, R. Poli, J. De Winter, P. Laurent, P. Gerbaux, P. Dubois, J.-P. Wathelet, C. Jérôme, C. Detrembleur, Chem. Eur. J. 2010, 16, 1799-1811. c) A. Debuigne, R. Poli, J. De Winter, P. Laurent, P. Gerbaux, J.-P. Wathelet, C. Jérôme, C. Detrembleur, Macromolecules 2010, 43, 2801-2813. 
[47] M. R. Perry, L. E. N. Allan, A. Decken, M. P. Shaver, Dalton Trans. 2013 42, 9157-9165.

[48] a) Z. Xue, R. Poli, ACS Symp. Ser. 2012, 1100, 231-242. b) Z. Xue, R. Poli, J. Polym. Sci. A Polym. Chem. 2013, 51, 3494-3504.

[49] S. Kanagasabapathy, D. Serero, D. Silie, S. Prost, R. Ruiz-Guerrero, J. Claverie, Res. Discl. 1998, P1595-P1604.

[50] D. N. Bunck, G. P. Sorenson, M. K. Mahanthappa, J. Polym. Sci., Polym. Chem. 2011, 49, 242-249.

[51] H. Kaneyoshi, K. Matyjaszewski, Macromolecules 2006, 39, 2757-2763.

[52] a) A. Debuigne, N. Willet, R. Jerome, C. Detrembleur, Macromolecules 2007, 40, 7111-7118. b) A. Debuigne, M. Schoumacher, N. Willet, R. Riva, X. M. Zhu, S. Rutten, C. Jerome, C. Detrembleur, Chem. Commun. 2011, 47, 12703-12705. c) A. Debuigne, A. N. Morin, A. Kermagoret, Y. Piette, C. Detrembleur, C. Jérôme, R. Poli, Chem. Eur. J. 2012, 18, 12834-12844.

[53] M. Hurtgen, J. Liu, A. Debuigne, C. Jerome, C. Detrembleur, J. Polym. Sci., Polym. Chem. 2012, 50, 400-408.

[54] a) Y. Piette, A. Debuigne, C. Jérôme, V. Bodart, R. Poli, C. Detrembleur, Polym. Chem. 2012, 3, 2880-2891. b) Y. Piette, A. Debuigne, V. Bodart, N. Willet, A. S. Duwez, C. Jerome, C. Detrembleur, Polym. Chem. 2013 4, 1685-1693.

[55] C. Detrembleur, A. Debuigne, M. Hurtgen, C. Jerome, J. Pinaud, M. Fevre, P. Coupillaud, J. Vignolle, D. Taton, Macromolecules 2011, 44 6397-6404.

[56] A. Kermagoret, A. Debuigne, C. Jerome, C. Detrembleur, Nature Chemistry 2014, 6, 179-187.

[57] A. N. Morin, C. Detrembleur, C. Jérôme, P. D. Tullio, R. Poli, A. Debuigne Macromolecules 2013, 46, 4303-4312.

[58] R. Poli, L. E. N. Allan, M. P. Shaver, Prog. Polym. Sci. 2014, 39, $1827-$ 1845.

[59] a) G. David, C. Boyer, J. Tonnar, B. Améduri, P. Lacroix-Desmazes, B. Boutevin, Chem. Rev. 2006, 106, 3936-3962. b) B. Améduri, Chem. Rev. 2009, 109, 6632-6686. c) F. Boschet, B. Améduri, Chem. Rev. 2014, 114 927-980.

[60] a) S. Aoshima, S. Kanaoka, Chem. Rev. 2009, 109, 5245-5287. b) A Kanazawa, S. Kanaoka, S. Aoshima, Chem. Lett. 2010, 39, 1232-1237. 


\section{Entry for the Table of Contents}

\section{CONCEPT}

Recent progress in organometallicmediated radical polymerization (OMRP) is outlined with focus on the achievements and perspectives in the controlled polymerization of "less active monomers" (LAMs).

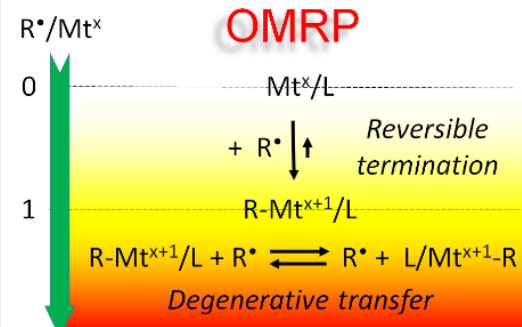

$\mathrm{R} \cdot \mathrm{Mt}^{\mathrm{x}} \quad$ OMRP

0

$\mathrm{Mt} \mathrm{t}^{\mathrm{x}} / \mathrm{t}$

$+\mathrm{R} \cdot \downarrow \uparrow \quad \begin{gathered}\text { Reversible } \\ \text { termination }\end{gathered}$

1 $\mathrm{R}-\mathrm{Mt} \mathrm{t}^{\mathrm{x}+1} / \mathrm{L}$

$\mathrm{R}-\mathrm{Mt}^{\mathrm{x}+1} / \mathrm{L}+\mathrm{R}^{\bullet} \rightleftarrows \mathrm{R}^{\bullet}+\mathrm{L} / \mathrm{Mt}^{\mathrm{x}+1}-\mathrm{R}$ Degenerative transfer

Rinaldo Poli*

Page No. - Page No.

New phenomena and perspectives in organometallic-mediated radical polymerization (OMRP) 


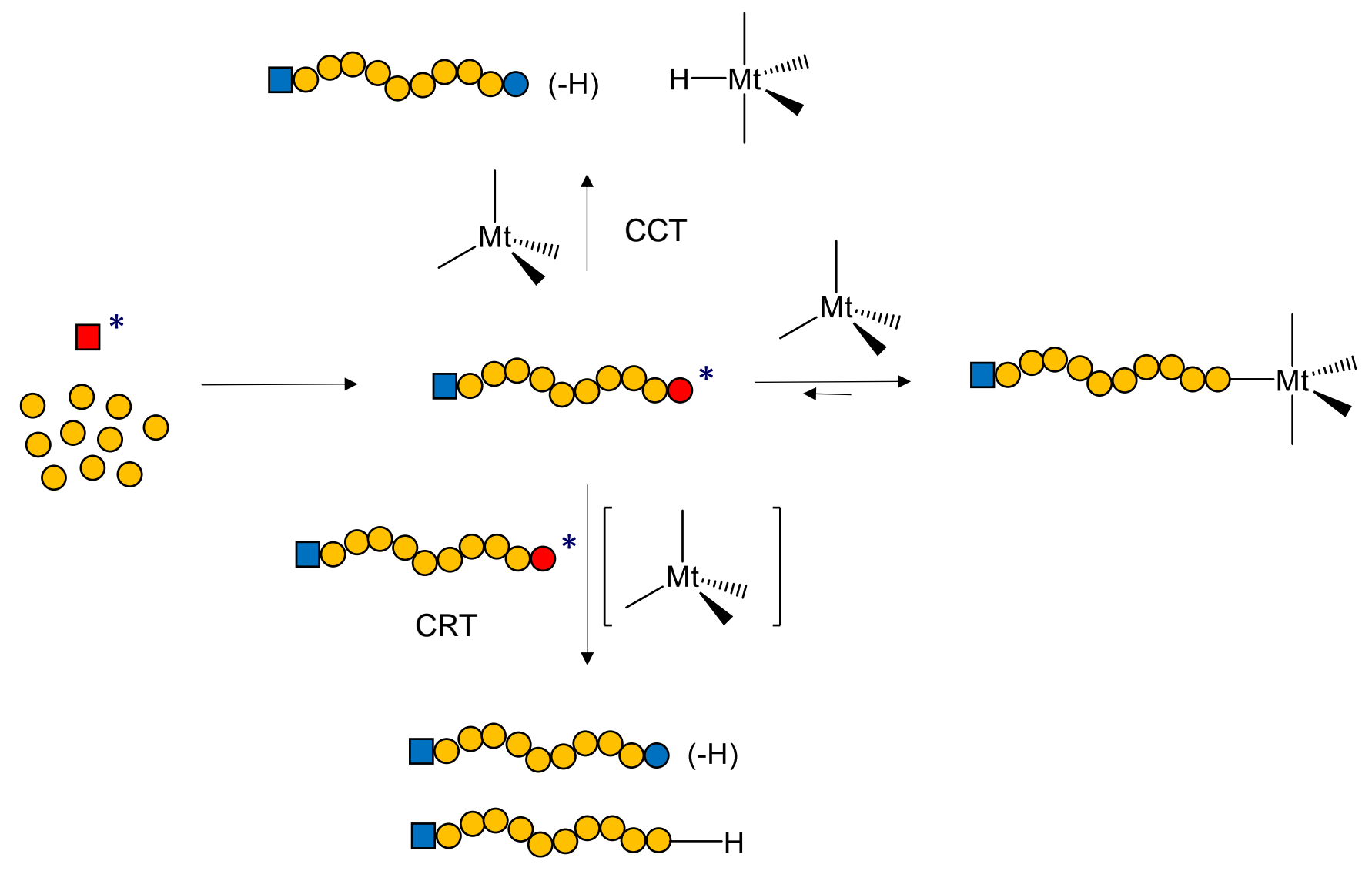

Text for the frontispice:

\section{Challenging polymers}

The controlled radical polymerization of "more active" unsaturated monomers such as styrenics, (meth)acrylates, acrylonitrile and others can now be easily achieved by various moderating methods but challenges remain in the control of "less-active" monomers. Organometallic mediated radical Polymerization (OMRP) has made high impact contribution in this area. The Concept article by R. Poli (page ....) highlights the advantages and pitfalls of the OMRP technique and highlights the remaining problems to be solved in order to further push the frontiers of controlled polymerization. 